\title{
Assessing the Plurality of Actors and Policy Interactions: Agent-Based Modelling of Renewable Energy Market Integration
}

\author{
Marc Deissenroth, Martin Klein, Kristina Nienhaus, and Matthias Reeg \\ German Aerospace Center, Institute of Engineering Thermodynamics, Department of Systems Analysis and Technology Assessment, \\ Pfaffenwaldring 38-40, 70569 Stuttgart, Germany
}

Correspondence should be addressed to Marc Deissenroth; marc.deissenroth@dlr.de

Received 2 June 2017; Revised 1 September 2017; Accepted 31 October 2017; Published 10 December 2017

Academic Editor: Liz Varga

Copyright (C) 2017 Marc Deissenroth et al. This is an open access article distributed under the Creative Commons Attribution License, which permits unrestricted use, distribution, and reproduction in any medium, provided the original work is properly cited.

\begin{abstract}
The ongoing deployment of renewable energy sources (RES) calls for an enhanced integration of RES into energy markets, accompanied by a new set of regulations. In Germany, for instance, the feed-in tariff legislation for renewables has been successively replaced by first optional and then obligatory marketing of RES on competitive wholesale markets. This paper introduces an agentbased model that allows studying the impact of changing energy policy instruments on the economic performance of RES operators and marketers. The model structure, its components, and linkages are presented in detail; an additional case study demonstrates the capability of our sociotechnical model. We find that changes in the political framework cannot be mapped directly to RES operators as behaviour of intermediary market actors has to be considered as well. Characteristics and strategies of intermediaries are thus an important factor for successful RES marketing and further deployment. It is shown that the model is able to assess the emergence and stability of market niches.
\end{abstract}

\section{Introduction}

Electricity and heat production are the main sources of worldwide $\mathrm{CO}_{2}$ eq emissions and hence one of the main drivers of anthropogenic climate change [1]. In order to ensure a successful transition of these sectors to carbon-free or low-carbon, a further expansion of the usage of renewable energy sources (RES) is needed [2]. To initiate the necessary investments and changes in technical, organizational, and financial regimes, various policy approaches are being discussed and implemented. In 2016, most countries in the world had RES targets or support policies in place [3].

As one of the earliest examples, the German government has adopted targets for the installation of renewables: by 2025 , the share of renewable energy in the electricity sector shall be expanded to $40-45 \%$ and to $55-60 \%$ by the year 2035 [4]. The most important policy instrument to achieve these targets is the Renewable Energy Sources Act (German: "Erneuerbare Energien Gesetz") (EEG), which was enacted in 2000 [5]. Its longevity and structural stability make it a fruitful case study to investigate energy policy in the field. In its original state, it mainly operated as a feed-in tariff (FiT) law which guaranteed a fixed remuneration for renewable energy sources for electricity (RES-E). It has been effective in fostering the deployment of RES-E [6]. Several amendments and revisions have been undertaken, such as, in 2012, when the German government introduced, for example, a monthly adjustment of feed-in tariffs for solar panels and an optional variable market premium to support the marketing from RES-E at the power exchange [7, 8] (see "The Market Premium" in the appendix).

The main intention of the EEG is to have a regulatory impact on the market conditions and the technoeconomic regime, as well as on the involved market actors who play a key role in the energy system's transition, as they provide the necessary investments in RES-E technologies. However, the invoked investment dynamics were not stable under all circumstances. With the fall of system prices and the accompanying relative sluggish adjustments of incentives, the deployment of solar plants in Germany went up from roughly $2.0 \mathrm{GW}$ in 2008 to $7.5 \mathrm{GW} / \mathrm{a}$ in the years $2010-2012$. The deployment went back to $1.9 \mathrm{GW}$ in 2014 [9], which created 
considerable market distortions and unstable investment behaviour.

The deployment and integration of RES can only be reliably regulated, as long as policy instruments do consider the interdependencies and interactions with and of the involved actors as well as the resulting market interplay on the investment dynamics. The motivation for the development of the agent-based model AMIRIS is therefore to study the adequacy of policy measures which affect the entities that comprise the electricity system; the aim is to examine the impact of policy on the involved market actors on the microlevel (e.g., income situation of renewable power plant operators) as well as their effects on the macrolevel (e.g., power exchange prices and market structure) [10].

The remainder of the paper is structured as follows. In Section 2, we will elaborate on the complexity of the energy system transition, and our motivation to choose an agent-based model (ABM) approach to address our research questions. Section 3 will give a brief overview of the AMIRIS model. For further detail, the technically interested reader can refer to Section 4, which describes the agents and their behaviours in detail. To exemplify the model's capabilities and questions to be addressed, Section 5 presents a case study on the marketing of RES-E at the power exchange and how an amendment of the policy regime affects market actors in different ways. Here we will show how the heterogeneity of agents, for example, different portfolios, affects the income and behaviour of the represented renewable electricity marketers and power plant operators. Section 6 discusses the case study and gives an overview of the lessons learned from the use of the ABM approach. Section 7 concludes with lessons learned from both the case study and the modelling approach in general.

\section{Modelling the Complexity of Energy Transitions}

2.1. Challenges of Modelling the Impact of Energy Policy Measures on the Behaviour of Actors. The pathway of the development of the global energy system, namely, the anticipated shift of supply from centralized fossil-fuelled power plants towards a decarbonised and RES dominated regime, is uncertain; many possible energy futures are conceivable [12]. Part of the uncertainty of which energy future will materialize results from the unexplored behaviour of the market actors who implement new technologies, as their relationships and intentions remain understudied. Bale et al. [13] state that "Energy systems can be understood as complex adaptive systems in that they have interrelated, heterogeneous elements (agents and objects). In addition, there is no autonomous control over the whole system, and, in that sense, self-organized emergent behaviour arises that cannot be predicted by understanding each of the component elements separately." As such, the result of markets at the macrolevel of the system is based on a variety of individual actions on the microlevel [14].

In Germany, individual options of choices and the number of actors in the system have increased substantially since the liberalization of electricity markets and the introduction of the EEG and its several amendments [17]. They decide under the influence of cognitive biases $[18,19]$ and inherent uncertainty and are therefore only bounded rational [20]. Policies are directed towards those actors to induce a desired collective behaviour and are uncertain in their effect as well.

Electricity is different to most other commodities, for at least two reasons: it is not storable at low costs, and the demand side is only marginally elastic. Hence, it is necessary to balance supply and demand on short notice at all times in order to ensure system stability. This situation got more challenging with the large-scale integration of RES-E into the system. Due to inherent output forecast limitations and their nondispatchability, RES-E can always be subjected to high balance energy cost due to day-ahead forecast errors and cannot hedge risks on future markets [21-24]. As such, additional intermediary market actors which specialize in forecasting and dispatching variable renewable energy (VRE) emerged. These intermediary market actors increased the order of complexity in the market.

Additionally complicating is the fact that diverse electricity markets, like spot and futures, control energy as well as $\mathrm{CO}_{2}$ certificates markets interacting with and influencing each other [25]. As a result, the heterogeneous power plant and marketing actors can react very differently to energy policy adjustments and the development of the electricity system as a whole can follow diverse pathways [26]. This is a tremendous challenge from a modelling perspective.

\subsection{Overview of Agent-Based Models in Energy System} Modelling. Given the challenges mentioned above, we have chosen an agent-based modelling (ABM) approach, which addresses these questions by placing the actors, their interrelationships, and their influencing environment in the centre of the modelling exercise [14]. The origin of the ABM approach is found in the field of artificial intelligence and cellular automata research and has been used for analysing complex and interrelated systems in such various research domains as ecology, social sciences, and software engineering [27]. The ABM approach enables the modeller to describe the complex relationships of the systems entities by identifying a set of attributes, behavioural rules, adaptations of those behavioural rules in response to the behaviour of others and the environment, and an environment itself [28]. The analysis is executed step by step and allows for developing these relationships on an evolutionary path in an artificial laboratorylike environment $[29,30]$. Agent-based models are therefore particularly suitable for the simulation of multiply linked and complex systems with autonomous actors. The system's behaviour is not centrally determined but evolves bottom-up from the actions taken by the individual agents to a complex system with emergent structures.

The ABM approach has been successfully applied in the energy sciences. Recent publications have investigated the role of certain technologies, like the market diffusion of PV $[31,32]$ and biomass power plants [33], or the value of storage technologies [34]. Others have put their focus on certain aspects of the demand side of the energy system, as this aspect is associated with a need for a more "human" modelling and preference depiction: their works focus on demand response 


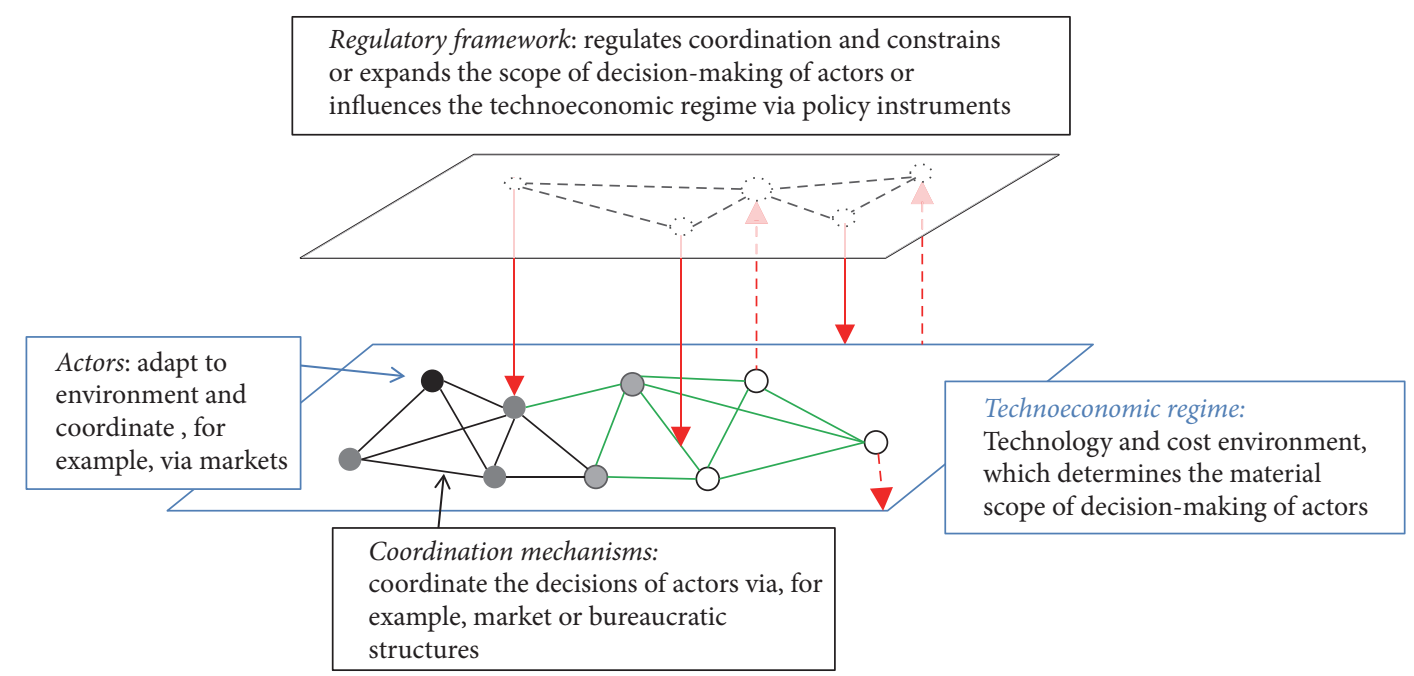

FIGURE 1: A sketch of the system that is represented by the AMIRIS model.

[35-37], adoption of dynamic tariffs [38], price elasticities [39], and smart meter diffusion [40], among others. Another branch focuses on energy trading on the balancing market [41], the merit order effect [42], emission trading and investment decisions [43], and forecasting [44, 45]. For a comprehensive review of energy market applications, the reader might want to refer to $[25,46]$ and to [47] for a special focus on newly emerging market structures.

2.3. Conceptual Approach of the AMIRIS Model. Figure 1 depicts the model's scope of analysis; it shows components and interrelations between actors, regulatory frameworks, technologies, and markets which are addressed by the simulation. The technoeconomic layer represents technologies and corresponding costs that are available to the actors of the energy system. It is characterized by technical parameters like efficiencies and durability values and cost parameters. In this sense, the technoeconomic layer determines what is technically feasible. Actors sketched as dots in the technoeconomic layer coordinate themselves, for example, via markets, like the spot market and balancing energy markets. They may set up contracts to invest in technologies and sell or buy energy.

The technoeconomic layer is influenced in several ways by the overlying regulatory framework layer, which may change the apparent costs of technologies by, for example, increase of research and development in certain technologies, deployment incentives like feed-in tariffs, or the financial promotion of RES-E direct marketing. The term direct marketing here refers to selling RES-E at market places for electricity via the market premium model under the EEG (see "The Market Premium" in the appendix). Furthermore, this layer may as well enhance or reduce actors action space by regulating markets or by setting up rules that prohibit certain decisions and behaviours of actors.

Solid arrows represent possible vectors of analysis, while dashed arrows are not explicitly incorporated in the model. More influences may appear in such a system that are not subject to the actual implementation, like, for example, feedback from actors to the regulatory level or impacts from actors onto the technoeconomic layer itself.

With the ambition to model the agents and the impact of policy framework adoptions in the process of market integration of RES-E, knowledge about the relevant actors and their expectations, motivations, and strategies is required. To depict the qualitative differences among market actors, systematic actors analysis has been carried out. The actors characteristics of RES-E power plant operators and direct marketers have been developed on the basis of document analysis and expert interviews $[10,48]$. These two agents types are modelled in detail compared to other (system) relevant actors of the power system (see Sections 3 and 4). The assumptions were then tested and reassessed in semistructured expert interviews with representatives from the most important actor groups, as well as in the context of an actor workshop. An exemplified version of the typecast of actors into agents is given in the case study in Section 5. The current state of the model will be presented in the following two sections.

\section{AMIRIS Model Overview}

3.1. Agent Topology. The model comprises two different types of agents: (a) agents with scope of decision-making and (b) agents without scope of decision-making. Type (a) agents are able to adapt to changed circumstances and may decide which action to perform. Contrary to this, type (b) agents have strictly defined tasks to perform during simulation from which they cannot deviate. The model covers the following type (a) and type (b) agents:

(i) Wind, solar, and biomass power plant operator agents as well as the thermal power plant operators generate electricity with their plants (type (a)).

(ii) Direct marketer agents trade electricity from RES on the power exchange market and control power market (type (a)). 

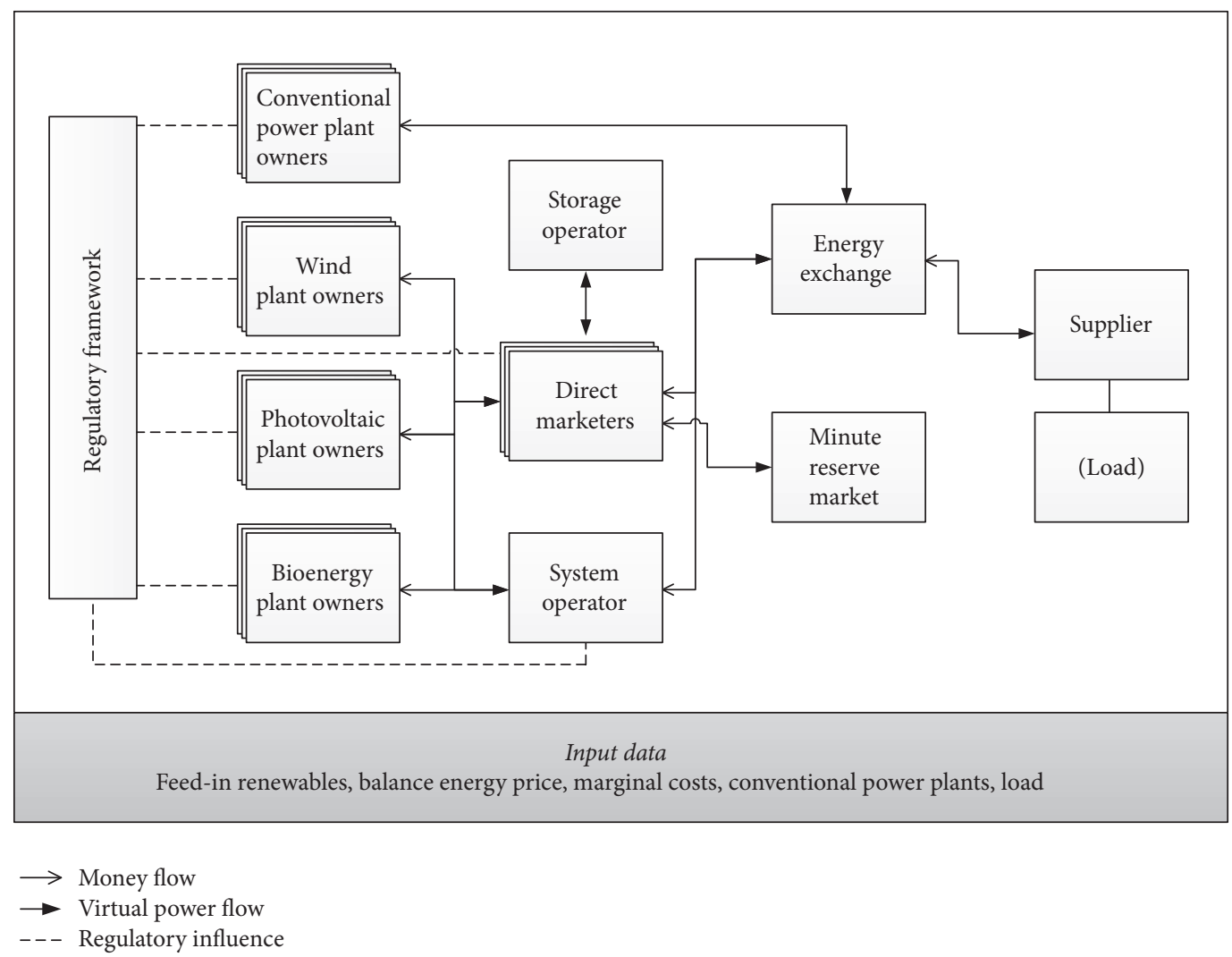

FIgURE 2: The AMIRIS model.

(iii) Optionally, a storage operator agent can be associated with a direct marketer that in turn can improve the operation and coordination of plants in her portfolio (type (a)).

(iv) The day-ahead power exchange market agent determines the wholesale power market price via a merit order model (its implementation is discussed in Section 4.3.2) (type (b)).

(v) The negative minute reserve market allows offering control power provision (type (b)).

(vi) The grid operator agent manages the generated electricity from wind, solar, and biomass which is not traded by direct marketers. It is sold mandatorily on the day-ahead power exchange market (type (b)).

(vii) The total load of the German power system serves as a static demand sink (type (b)).

(viii) The regulatory framework agent holds information about the total installed power in the system, the remuneration schemes, and undertakes calculations according to the EEG (type (b)).

The agents interact in a changing environment influenced by the energy policy framework of the Renewable Energy Sources Act (EEG) and its corresponding RES-E support scheme as well as the Energy Industry Act [49] and grid regulations. Figure 2 gives a schematic overview of the model interconnections. Boxes represent agents in the model; multilayered boxes indicate that these agent types have multiple instances during the course of simulation. Solid lines represent money and power flows, which are differentiated by open and closed arrows, respectively. Regulatory influence is depicted with dashed lines. Wind, PV, and biomass power plant operators (PPOs) can sell electricity either to the direct marketer or to the grid operator.

As the focus of the AMIRIS model is to investigate the effects of the market integration process of renewable energy sources on the involved actors, the cost and revenue structure of marketers that trade electricity from RES-E PPOs are implemented in detail and will be discussed in Section 4.2.1. PPOs can sign contract with direct marketers and switch contracts at the beginning of each year if a better offer is received (see also Section 4.2.2).

3.2. Process Overview and Scheduling. The model has a onehour time resolution and is usually run over the course of 8-20 calculative years. Computation time on a conventional desktop computer is in the order of minutes. Internal time is set by the regulatory framework class. The following steps are calculated each time frame, which equals one calculative hour:

(i) Generated electricity and its virtual distribution to direct marketers or to grid operator are determined.

(ii) The residual load, the merit order, and corresponding wholesale power market price are calculated. 
TABLE 1: External input parameters for the AMIRIS model. $l$ indicates the type of the primary product as follows: $l=1:$ uranium, $l=2:$ lignite, $l=3$ : coal, and $l=4$ : gas. Index $i$ defines the power plant type with $i=1$ : nuclear, $i=2$ : lignite, $i=3$ : coal, $i=4$ : combined cycle gas turbine (CCGT), $i=5$ : open cycle gas turbine (OCGT), $i=6$ : offshore wind, $i=7$ : onshore wind, $i=8$ : photovoltaics, and $i=9$ : biomass.

\begin{tabular}{|c|c|c|}
\hline Parameter & Description & Unit \\
\hline$C_{\text {prim }}^{l}(t)$ & Time series of costs of the primary products used for the calculation of the stock market prices & {$[€ / \mathrm{MWh}]$} \\
\hline$C_{\text {carb }}(t)$ & Time series of cost for carbon dioxide emission certificates & {$\left[€ / t_{\mathrm{CO} 2}\right]$} \\
\hline$C_{\mathrm{var}}^{i}(t)$ & Time series of variable costs of conventional power plant of type $i=1-5$ & {$[€ / \mathrm{MWh}]$} \\
\hline$\eta_{\min }^{i}(t)$ & Time series of minimal efficiency of conventional power plant of type $i=1-5$ & [\%] \\
\hline$\eta_{\max }^{i}(t)$ & Time series of maximal efficiency of conventional power plant of type $i=1-5$ & [\%] \\
\hline$w^{i}(t)$ & Normalized generation potential time series for $i=6,7,8$ & [\%] \\
\hline$\alpha^{i}$ & Availability factor to regard shut-down periods $\left(\alpha^{1}=0.8, \alpha^{2}=0.8, \alpha^{3}=0.7, \alpha^{4}=0.7\right.$, and $\left.\alpha^{5}=1.0\right)$ & - \\
\hline $\mathrm{PR}_{\mathrm{bal}}(V)$ & Histogram of 2011 prices for balancing energy & [€/MWh] \\
\hline$c_{\text {mark }}$ & Costs for marketing & {$[€]$} \\
\hline$c_{\text {IT }}$ & Costs for IT & {$[€ / a]$} \\
\hline$c_{\text {trade,var }}$ & Costs of charges for trading at the exchange market & {$[€ / \mathrm{MWh}]$} \\
\hline$c_{\text {trade, fix }}$ & Costs for permission of trading at the exchange market & {$[€ / \mathrm{a}]$} \\
\hline$c_{\text {liab }}$ & Costs for the liability of equity to be able to trade at the exchange market, payed once & {$[€]$} \\
\hline$c_{\text {pers,spec }}(V)$ & Specific costs for personnel depending on traded volume & [€/MWh] \\
\hline$c_{\mathrm{fcst}}(\mathscr{P})$ & Costs for forecast of electricity generation volume dependent on installed capacity & [€/MW] \\
\hline$M(t)$ & Time series of management premium according to the EEG & {$[€ / \mathrm{MWh}]$} \\
\hline$R(t)$ & Time series of remuneration for renewable energy power plants according to the German Renewable Energy Act & {$[€ / \mathrm{MWh}]$} \\
\hline$P_{\text {inst }}^{i}(t)$ & Time series of installed power of corresponding technology $i$ & {$[\mathrm{MW}]$} \\
\hline$D(t)$ & Time series of demand for Germany & {$[\mathrm{MW} / \mathrm{h}]$} \\
\hline$G^{i}(t)$ & Power generation in $t$ from technology $i$ & [MWh] \\
\hline
\end{tabular}

(iii) The grid operator calculates the marginal capacity price for the control power provision of the negative minute reserve market by a regression model.

(iv) With an appropriate portfolio, marketers can offer firm capacity at the control power market.

(v) Revenues and costs are assigned to the marketers and the power plant operators.

(vi) Marketers forecast the electricity production of their portfolio and estimate the market price at $t+24 \mathrm{~h}$ and decide on curtailment of contracted RES-E power plants.

3.3. Modelling Framework. AMIRIS uses the free and open source agent-based modelling and simulation development framework Repast Simphony, which facilitates model design, execution, and data export and serves as an initial context builder for our model. Repast Simphony has been conjointly developed by the University of Chicago and Argonne National Laboratory [50]. It is available directly from the web (http://repast.sourceforge.net/ (last accessed: 23.09.2015)) and licensed under "new BSD" ("New BSD" is a BSD 3-Clause License; see https://opensource.org/licenses/BSD-3-Clause (last accessed: 23.09.2015)). The model is implemented in the Java programming language (http://www.oracle.com/ technetwork/java/index.html (last accessed: 23.09.2015)).

\section{Agents and Input Data}

4.1. Input Data. At initialization of the program several data files are read according to the scenario under investigation.
The files contain time series and lists as shown in Table 1 that can be categorized as input for (a) the electricity generation from renewable and conventional power plants, (b) the calculation of marginal costs of conventional power plants, (c) the direct marketers' typecast, and (d) the regulatory framework. The total installed power in the system $P_{\text {inst }}(t)$ for all types of technologies is based on a study for the Federal Ministry of Environment, Nature Conservation, Building and Nuclear Safety covering long term scenarios of renewable energy plant deployments in Germany [51]. For conventional power plants, the installed power is multiplied by an availability factor to take shut-down periods into account. In order to represent the electricity generation of fluctuating renewable power plants, normalized generation potential time series $w(t)$ for wind and solar are used. These generation time series are derived by the EnDat module of the energy system model REMix $[52,53]$. EnDat uses a historic weather time series containing wind speeds and solar radiation of the year 2006 that is processed with characteristic system curves for wind and photovoltaic power plants in Germany [52]. In the model, the shape of the demand curve $D(t)$ is represented by the total German electricity demand of 2011 [16]. The scale can be varied according to the underlying scenario study. Marginal costs are determined regarding fuel specific costs and additional variable costs as well as costs for carbon dioxide emission certificates. Fuel specific costs are calculated by primary product costs and efficiencies for correspondent technologies. The calculations' underlying scenarios are found in [51], and details on the applied values are given in [10]. 
Costs $c$ for various marketing services for compensations are represented in Table 1 and used for a typecast of the cost structure of actors. The use of the various cost parameters is described further in Section 4.2.1.

The input for the regulatory framework is given by a time series $M(t)$ containing the management premium and its decrease over time [54] (compare also "Revenue" in Section 4.2.1). The Renewable Energy Sources Act [4] and its remuneration schemes for different technologies are represented by time series $R(t)$.

\subsection{Agents with Scope of Decision-Making}

4.2.1. The Direct Marketing Agents. In the process of simulation, the direct marketer agents have the possibility of basing their decisions on the current market conditions. The marketer's business is to profitably sell renewable electricity at the power exchange market. Success or failure of their businesses is evaluated by the profits $p(t)$, which is the difference between revenues $i(t)$ and $\operatorname{costs} c(t)$ :

$$
p(t)=i(t)-c(t) \text {. }
$$

The typecast parameters shown in Table 2 allow a representation of the real market actors heterogeneity. Different types of marketers with diverse revenue and cost structures (compare Section 5) are implemented in the model. The forecast quality of a marketer, described by $\sigma$ and $\mu$, is crucial for a successful business. By reducing forecast errors, balancing energy procurement costs can be minimised.

Revenue. Revenues can be generated by the support scheme as well as on two markets: the power exchange market and the control energy market, with revenues $i_{\mathrm{XM}}$ and $i_{\mathrm{CE}}$, respectively. In reality the control energy market consists of the primary, secondary, and minute reserve markets. On these pay-as-bid markets, participants can offer control power to the system operator for grid stability requirements. The balancing energy market determines the cost (or incomes) for a trader or supplier that deviates from their dayahead schedule within its corresponding balancing region. Balancing market prices are determined by control energy demand requirements of the system operator. Hence, it is rather an accounting system than a market.

Additional regulated revenues are derived from payouts of the management premium $M(t)$ for direct marketing. Within the implementation of the market premium scheme in the year 2012, the management premium has been introduced as additional entity for compensating for the costs associated with direct marketing duties compared to the FiT scheme (see "The Market Premium" in the appendix). The more efficiently direct marketers fulfill their marketing services for RES-E power plant operators (PPO), the higher the decision scope for either increasing their own profits or the bonus payments to their associated PPOs (see also "Bonus Payments" below).

Whereas the power exchange market represents the marketer's primary source of revenue, participation in the control energy market is optional. The model allows for the participation in the negative minute reserve market
TABLE 2: Variables describing properties of direct marketers. Variations of variable values are used to define the type of marketer and to reflect heterogeneity of actors.

\begin{tabular}{|c|c|c|}
\hline Variable & Unit & Description \\
\hline$\sigma_{\text {price }}$ & & $\begin{array}{c}\text { Uncertainty of price } \\
\text { forecast of direct marketer, } \\
\text { depending on the traded } \\
\text { volume } V \text { with values } 0.15 \text {, } \\
0.2 \text {, or } 0.25\end{array}$ \\
\hline$\sigma_{\text {power }}$ & & $\begin{array}{c}\text { Uncertainty of power } \\
\text { forecast of direct marketer } \\
\text { with values } 0.15,0.2 \text {, or } 0.25\end{array}$ \\
\hline$\mu_{\text {power }}$ & & $\begin{array}{c}\text { Estimated value of power } \\
\text { forecast of direct marketer } \\
\text { with values } 0.05,0.1 \text {, or } 0.15\end{array}$ \\
\hline $\mathscr{P}$ & {$[\mathrm{MW}]$} & $\begin{array}{l}\text { Power generation portfolio } \\
\text { of marketer, that is, } \\
\mathscr{P}=\sum_{\tau, \mathrm{rc}} \mathscr{P}_{\tau, \mathrm{rc}} \text { of } \\
\text { technologies } \tau \text { in } \\
\text { remuneration classes rc }\end{array}$ \\
\hline $\mathscr{C}$ & {$[€]$} & Initial capital of marketer \\
\hline
\end{tabular}

(due to opportunity costs with the day-ahead spot market biddings and the required curtailed operation mode, positive reserve provision is financially not attractive for RES-E plant operators and is therefore not modelled). The marginal capacity price at which bids of the direct marketing agents are accepted is determined by the grid operator agent every fourth simulated time step by a multiple linear regression model (compare Section 4.3.1).

The direct marketing agents can follow two bidding strategies to maximize profits:

(i) "Low-Risk-Strategy": with this strategy marketers offer a capacity price on the pay-as-bid market corresponding to the median of the preceding month's 180 $4 \mathrm{~h}$-price-blocks. This way acceptance of a bid is very likely but only at a relative low capacity price $\Pi_{\mathrm{CE}}$.

(ii) "High-Risk-Strategy": with this strategy marketers offer a capacity price on the pay-as-bid market corresponding to the median of the preceding month's 180 4 h-price-blocks plus the standard deviation of these prices. This way acceptance of a bid is less likely but in case of acceptance a relatively high capacity price $\Pi_{\mathrm{CE}}$ is ensured.

Further revenue $i_{\text {bal }}(t)$ can originate in case the own local imbalance can reduce the imbalances of the corresponding balancing grid region.

Costs. Both fixed and variable costs are considered in the total cost determination. For yearly fixed costs $c_{\text {fix }}$, IT and trading permission are regarded. Further, upon starting the direct marketing business, the marketer has to provide a liable equity. The different positions of variable costs depend primarily on the amount of electricity traded by the direct marketer. Trading fees are to be paid for each traded MWh, 


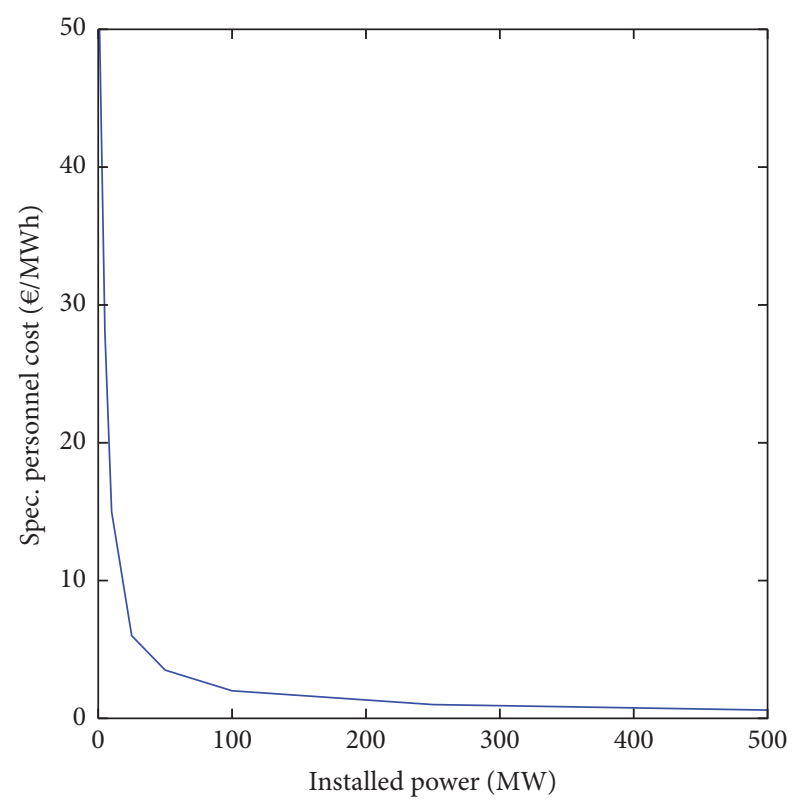

(a)

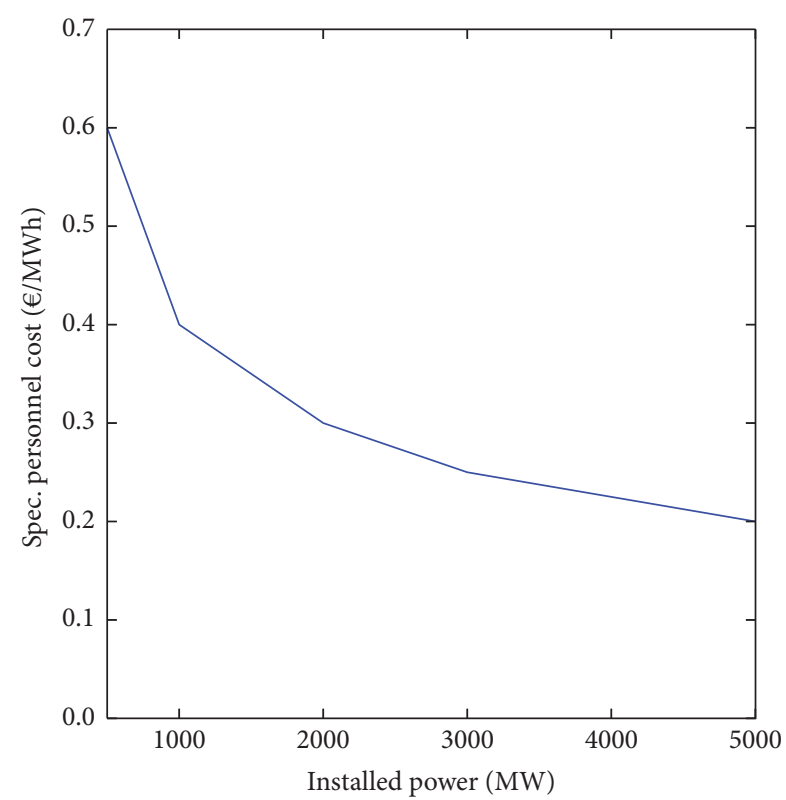

(b)

FIGURE 3: Specific personnel costs $c_{\text {pers,var }}$ per installed capacity of the marketers in the model. Data from [11].

whereas costs for balancing energy depend on the deviation between the forecast and actual VRE generation.

The balancing energy price is determined at each time step by the grid operator by uniform random selection out of a price histogram based on balancing energy prices of the year 2011 in Germany. The balancing price as well as the balancing volume may take negative and positive values; thus balancing costs can contribute to the marketers' revenue for $c_{\text {bal }}(t)<0$ and $i_{\text {bal }}(t)=-c_{\text {bal }}(t)$ (see also (A.1) in the appendix).

Payments for balancing energy and expenses for the staff and IT are the largest cost positions for direct marketers [11]. The specific personnel costs reveal substantial economies of scale and range from several $€ / \mathrm{MWh}$ for portfolios smaller than $50 \mathrm{MW}$ to only €cents/MWh for $+500 \mathrm{MW}$ of contracted VRE capacities (compare Figure 3). Additionally, expenses for the power output forecast $c_{\mathrm{fcst}}$ affect the profit calculation. As direct marketers mainly manage a generation portfolio and do not own the corresponding plants, a competition for acquisition of generation plants follows. To bind customers and to be financially attractive to potential new customers, marketers make bonus payments for the contracted power plant operators, another cost factor described in the following section.

Bonus Payments. At the start of the simulation, the bonus is defined to be half of the management premium of the corresponding year; that is, $c_{\text {bonus }}(t=0)=(1 / 2) M(t=0)$. In order to guarantee the direct marketer flexibility and control over costs, bonus payments can be adopted at the end of each simulated year. Within each adoption process the specific operating results $\beta\left(\mathrm{OR}_{\mathrm{spec}}\right)$ are evaluated. Further, the ratio of capital to operating results may additionally adjust the bonus payouts by $\beta^{\prime}\left(\mathrm{OR}_{\text {capital }}\right)$ in case of negative operating results.
TABLE 3: Definition of bonus parameters $\beta$ and $\beta^{\prime}$ depending on operating results $(\mathrm{OR})$; that is, $\mathrm{OR}_{\text {capital }}=\mathscr{C} / \mathrm{OR}$.

\begin{tabular}{lccc}
\hline $\mathrm{OR}_{\text {spec }}[€ / \mathrm{MWh}]$ & $\beta$ & $\mathrm{OR}_{\text {capital }}$ & $\beta^{\prime}$ \\
\hline$\geq 1.0$ & 1.1 & 0 & 0.0 \\
{$[0.6,1.0[$} & 1.05 & ] $0-1]$ & 0.5 \\
{$[0.4,0.6[$} & 1.00 & ] $1-2]$ & 0.7 \\
{$[0.2,0.4[$} & 0.95 & ] $2-3]$ & 0.8 \\
$<0.2$ & 0.90 & ] $3-4]$ & 0.875 \\
& & ] $4-5]$ & 0.95 \\
\hline
\end{tabular}

The values for the bonus adjustments are given in Table 3 . The bonus does not merely increase the profit margins of the marketers; instead, they will invest their surpluses to increase the bonus payouts for the PPOs if the specific operational results are larger than 0.5 euro/MWh. This definition ensures a competition between the marketers seeking to attract new PPOs. In the model, bonus costs are thus calculated by

$$
\begin{aligned}
& c_{\text {bonus }}(t) \\
& = \begin{cases}c_{\mathrm{bonus}}(t-1) \cdot \beta\left(\mathrm{OR}_{\mathrm{spec}}\right) \cdot \beta^{\prime}\left(\mathrm{OR}_{\text {capital }}\right) & \text { for } \mathrm{OR}<0, \\
c_{\mathrm{bonus}}(t-1) \cdot \beta\left(\mathrm{OR}_{\mathrm{spec}}\right) & \text { for } \mathrm{OR} \geq 0 .\end{cases}
\end{aligned}
$$

Curtailment. The AMIRIS model allows for a market-driven curtailment of RES-E according to the incentives of the implemented policy instrument. In case of potentially high renewable electricity generation and low demand, the marketer may decide to switch off plants of her portfolio to avoid payments due to negative wholesale electricity prices 
(compare Section 4.3.2). The marketer's decision is based on a price forecast, given by

$$
\Pi_{\mathrm{fcst}}(t)=\Pi_{\text {perf }}(t+24) \cdot\left(1+\sigma_{\text {price }} \cdot g\right),
$$

with the random error variable $g$ drawn from a normal distribution times the perfect foresight price $\Pi_{\text {perf }}(t+24)$. Plant specific opportunity costs for curtailment determine whether RES-E generation is being curtailed. The estimation of these costs depends on the variable market premium $F(t)$ and the management premium $M(t)$ according to

$$
\left|\Pi_{\mathrm{fcst}}(t)\right| \geq F(t)+M(t) \quad \text { for } \Pi_{\mathrm{fcst}}(t)<0 .
$$

In case the sum of both premiums is lower than or equal to the absolute value of the forecast wholesale power market price $\Pi_{\text {fcst }}(t)$, the direct marketer will advise the corresponding PPOs to shut-down generation.

4.2.2. The RES-E Power Plant Operator Agents. The potential generation of electricity from renewables is given by the plant operator's installed capacity $\mathscr{P}_{\mathrm{rc}, \tau}$ multiplied by a normalized weather time series $w^{i}(t)$ :

$$
G_{\mathrm{rc}, \tau}(t)=\mathscr{P}_{\tau, \mathrm{rc}}(t) \cdot w^{i}(t),
$$

with $i=\tau$ in this case.

Plant operator agents are distinguished primarily by the generation technology $\tau$ in operation, that is, plants using wind, solar radiation, or biomass, as well as by the corresponding remuneration class $\mathrm{rc}$ the technology is assigned to (see also Section 4.3.4). The height of the remuneration class $\mathrm{rc}$ is calculated from empirical data about historical developments of FiTs and so-called "values to be applied" (replacing the FiT in the direct marketing regime) [55]. Each RES-E technology is subdivided in four representative remuneration classes, since the remuneration for a specific plant depends on the year of installation, the resource site, the type and size of the technology, and the energy carrier in use (the resource site is taken into account for wind power plants; the type and size of technology is relevant for PV and biomass plants and the energy carrier in use for biomass plants only). Table 4 lists all characterizing parameters for the renewable power plant agents. Their revenue is based on the remuneration of the fed-in electricity as well as on the bonus payments $i_{\text {bonus }}$ they receive from the direct marketers. The value of $i_{\text {bonus }}$ corresponds to the costs of the marketer $c_{\text {bonus }}$. PPOs opting for direct marketing receive new bonus offers at the beginning of each year from different direct marketing agents (see also "Bonus Payments" in Section 4.2.1). To capture transaction costs when switching the partnering agent, the difference between the old and new bonus offer must at least exceed a certain threshold $x_{\min }$. This threshold increases with the height of the remuneration class $\mathrm{rc}$, as the relative attractiveness of additional bonus payments correlates directly with the height of remuneration an agent is already receiving (see also Section 5).

4.3. Agents without Scope of Decision-Making. Figure 2 shows all agents in the AMIRIS model. Direct marketers and power
TABLE 4: Variables that characterize the type of renewable power plant agents.

\begin{tabular}{lcc}
\hline Variable & Unit & Description \\
\hline$\tau$ & - & $\begin{array}{c}\text { RES-E technology of the } \\
\text { power plant operator }\end{array}$ \\
\hline rc & - & $\begin{array}{c}\text { Remuneration class this } \\
\text { agent is assigned to }\end{array}$ \\
\hline $\mathscr{P}_{\tau, \mathrm{rc}}(t)$ & {$[\mathrm{MW}]$} & $\begin{array}{c}\text { Installed capacity of this } \\
\text { technology in the } \\
\text { corresponding }\end{array}$ \\
& & remuneration class \\
\hline & & $\begin{array}{c}\text { Threshold which needs to } \\
\text { be exceeded by a new } \\
\text { bonus offer in order to }\end{array}$ \\
& & switch contracts with direct \\
& marketers
\end{tabular}

plant operators are implemented with heterogeneous characteristics. They have several options for decision-making. Nevertheless, other agents without scope of decision-making are inevitable to complete the electricity systems representation. Hence, they hold important information for the hole systems functionality. They perform model endogenous calculations that are not subject to their own pursuit of strategic goals like revenue maximization.

4.3.1. Grid Operator Agent. According to the Ordinance on a Nationwide Equalisation Scheme (German: "Ausgleichsmechanismusverordnung") [56], the grid operator is responsible for the settlement of the support schemes in place and the payouts of FiTs and market premiums to the PPOs or direct marketers, respectively. He calculates ex post the height of the market premium for each remuneration class rc. For this, he receives the past months market values $M V_{\tau}$ of the VREs from the wholesale power market agent.

The agent also determines the balance energy price by uniform random selection of $\mathrm{PR}_{\mathrm{bal}}$. Additionally, the grid operator conducts the auctions for the negative minute reserve market. The marginal capacity price $\mathrm{MCP}_{\mathrm{CE}}$ is determined by a multiple linear regression model with the independent variables of the wholesale power market price $x_{1}$, the load $x_{2}$, and the onshore wind feed-in $x_{3}$ :

$$
\begin{aligned}
\operatorname{MCP}_{\mathrm{CE}}(t)= & -\alpha_{1} \cdot \frac{\sum_{t=h}^{t+4} x_{1, h}}{4}-\alpha_{2} \cdot \frac{\sum_{t=h}^{t+4} x_{2, h}}{4}+\alpha_{3} \\
& \cdot \frac{\sum_{t=h}^{t+4} x_{3, h}}{4}+\beta
\end{aligned}
$$

with $\alpha_{1}=0.5304, \alpha_{2}=0.0029, \alpha_{3}=0.0005$, and $\beta=154.1$.

The estimation of the regression parameters $\alpha$ has been derived from the negative minute reserve prices of the year $2011[10]$.

4.3.2. Wholesale Power Market Agent. The agent representing the power exchange market defines the wholesale power price every time step and disburses the market revenue to the corresponding agents according to the uniform market clearing 
TABLE 5: Associated residual loads, RL, and wholesale power prices according to analysis of market situations with low (0-20€/MWh) and negative $(<0 € / \mathrm{MWh})$ prices in Germany $2011[15,16]$.

\begin{tabular}{lcccccccccc}
\hline Power price $[€ / \mathrm{MWh}]$ & 20 & 10 & 5 & 0 & -5 & -10 & -30 & -50 & -75 & -100 \\
RL intervals $[\mathrm{GW}]$ & 29.6 & 27.1 & 26.6 & 26.1 & 25.7 & 20.7 & 15.7 & 11.7 & 8.7 & 6.7 \\
\hline
\end{tabular}

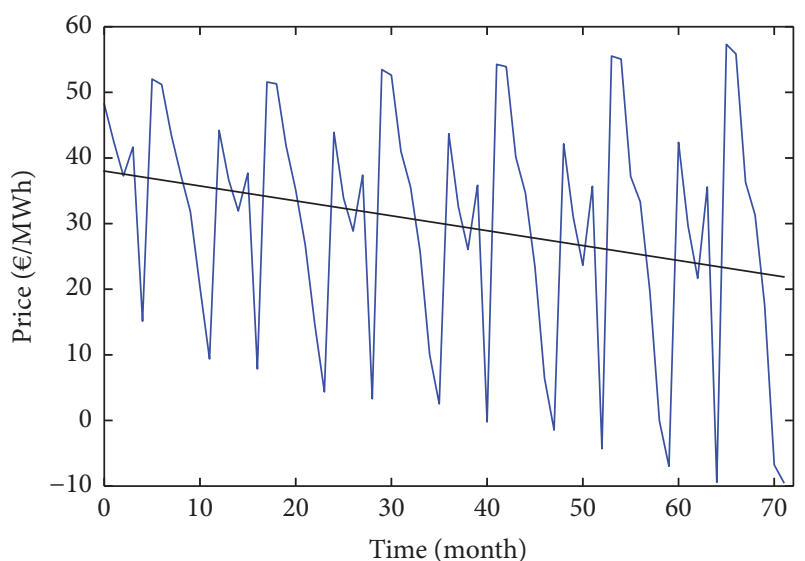

FIGURE 4: Average monthly wholesale power market prices generated by the model (the underlying data input is given in the case study Section 5). The line represents a linear fit to the data.

price $\mathrm{MCP}_{\mathrm{XM}}$. For the calculation of the $\mathrm{MCP}_{\mathrm{XM}}$ a merit order model is implemented. The merit order calculation is based on the residual load and the marginal costs of the conventional power plants $\mathrm{MC}_{\mathrm{PP} \text { conv }}$. Marginal costs of each power block $q$ of $200 \mathrm{MW}$ are set by (see also Table 1)

(i) fixed and variable costs of primary products $C_{\text {prim }}(t)$ (including fuel transportation or shipping);

(ii) certificate costs of carbon dioxide emissions $C_{\text {carb }}(t)$;

(iii) efficiencies $\eta(t)$ of the power plants;

(iv) other variable costs $C_{\text {var }}(t)$ (i.e., for insurance, etc.).

Once these costs are determined, they are ordered from the lowest to the highest value. The $\mathrm{MCP}_{\mathrm{XM}}$ is set by the last $200 \mathrm{MW}$ power bloc $q$ needed to satisfy the residual load:

$$
\mathrm{MCP}_{\mathrm{XM}}(t)=\min \left(\mathrm{MC}_{\mathrm{PP} \text { conv }} \mid \sum_{i=1}^{n} q_{i} \leq \mathrm{RL}\right) .
$$

Simulated average monthly clearing prices are shown in Figure 4 for the years 2014 to 2019. Over the course of the simulation the price-spread increases due to rising $\mathrm{CO}_{2}$ certificate and fossil fuel prices but the average price decreases due to the increased VRE feed-in with marginal costs of approximately $0 € / \mathrm{MWh}$. The general structure of the price curve reoccurs annually because only one representative weather year and load profile are used.

Conventional must-run (must-run capacities are due to power plants that offer complementary goods on other markets (like ancillary services or heat) and therefore need to be present in the wholesale market at all times, irrespective of very low or negative wholesale market prices) capacity is included via the definition of so-called "residual load intervals." The residual load intervals have been derived from the analysis of market conditions in which wholesale market prices have dropped below $20 € / \mathrm{MWh}$ (reference year 2011, [10]). If the lower-bound of an interval boundary is exceeded in a specific hour, the regular $\mathrm{MCP}_{\mathrm{XM}}$ calculation mechanism described above is replaced by the associated price of the corresponding residual load interval. Table 5 gives the residual load reference values and its associated wholesale power prices of the year 2011 in Germany. Over the course of the simulation, the interval boundaries decrease from year to year according to the development of the retirement of conventional base-load capacities in [51].

The calibration of the power exchange model is conducted by markups and markdowns of the conventional power plant agents, which are added to or subtracted from the $\mathrm{MC}_{\mathrm{PPconv}}$ values. The validation of the merit order model can be found in [10].

4.3.3. Demand Side Agent. The model's demand side is represented by a time series comprising total load values for each simulation step. The annual total energy consumption is scaled according to scenario A values from [51].

4.3.4. Regulatory Framework Agent. The regulatory framework agent holds all the energy policy information necessary for simulating the market integration process of RES-E. The law differentiates the remuneration for PPOs dependent on the general type of the RES-E technology installed, the potential full-load-hours at the installation site for wind onshore plants, the size of the plant for PV plants, and the chosen technology of biomass plants as well as on the corresponding biomass substrate in use [4]. In addition, as remunerations decrease over the years (since 2012 the decrease of remunerations for wind onshore and PV plants is carried out on a quarterly or even monthly basis) a complicated payout structure has evolved in reality since 2000 . As a consequence, by the year 2017, there are over 5.000 different remuneration categories within the EEG support scheme and about 1.5 Mio. RES-E power plants in place [55].

A mapping of plants to actors in every detail would require knowledge about each owner, plant type, and remuneration for each plant. Besides the fact that such information is, if at all, not easy to access, mapping of all PPOs individually would lead to a multiagent system (MAS) with over a million agents to be parametrized.

Therefore, four different remuneration classes are defined for each year and each renewable technology type $\tau$. This more homogeneous assignment allows for a transparent handling of the remuneration schemes in the model. Each class contains information about the remuneration, the technology, and the corresponding installed power. 
TABLE 6: Table representing the direct marketers' initial portfolios.

\begin{tabular}{lccc}
\hline Direct marketer & BM [MW] & PV [MW] & Wind [MW] \\
\hline Big utility & 522 & 1697 & 14145 \\
Municipal utility & 904 & 3394 & 8492 \\
Small municipal utility & 395 & 3394 & 1619 \\
Green electricity provider & 930 & 1697 & 3237 \\
Startup & 2602 & 23759 & 6873 \\
\hline
\end{tabular}

The regulatory framework agent saves and updates this information at the beginning of each year and remits the relevant data to the grid operator agent, who is in charge for the payouts of the support instrument in place (see also Section 4.3.1). Further, the agent calculates the reference market values $\mathrm{MV}_{\tau \text {,ref }}$ on a monthly basis and governs the height of the management premium (compare "The Market Premium" in the appendix).

\section{Case Study}

5.1. Model Setup and Agent Parametrization. In this section a case study shall demonstrate the model's basic working mode and give an example for possible fields of analyses. The case study examines the effects of a change in the regulatory framework, taking into account the interplay of the power plant owners and their possibility of changing their contracted direct marketers.

The regulatory framework refers to the market premium under the German Renewable Energy Sources Act (EEG) in its version of 2012 [7], when the market premium scheme has been introduced. Two variations of the correspondent management premium are analysed. In "Scenario 1," the level of the management premium $M(t)$ for variable (VRE) and dispatchable renewables is set to $3.7 € / \mathrm{MWh}$ and $1.125 € / \mathrm{MWh}$, respectively, in accordance with the initial values of the EEG 2012. In "Scenario 2," $M(t)$ for VRE is reduced by $50 \%$ to $1.85 € / \mathrm{MWh}$; for dispatchable renewables no changes are assumed. This decrease of the management premium for VRE reflects the decision of policymakers in 2012 when figuring out that the original height of $M(t)$ has led to considerable windfall profits for wind PPOs.

On the basis of an actor analysis [10, 48] (compare Section 4.2.1), five different types of direct marketers were aggregated for this case study: (1) big utility, representing big and medium power supply companies; (2) municipal utility; (3) small municipal utility; (4) green electricity provider; and (5) startup. The technology specific size of the portfolios is linearly growing each month according to the underlying time series of installed power of each technology. These numbers are based on empirical data on the number of plant operators receiving FiTs or market premiums published by the grid operators in Germany [55]. In the simulation, yearly changes in portfolio sizes and composition might take place due to the marketers' competition for PPOs. The simulation period for the case study is set to 2014 to 2019.

The initial technology specific composition of the portfolios for the starting year 2014 is displayed in Table 6. A more detailed resolution disclosing corresponding remuneration classes can be found in Table 9. Other important differentiation factors are the direct marketers' specific forecast capabilities as well as their capital resources (compare Section 4.2.1 and the appendix). Their initial parametrization is given in Table 7.

In Section 4.2.1, we describe how the bonus payments of marketers are changing throughout the simulation. The PPOs can cancel their contract at the end of each simulation year and enter into a new contract with another direct marketer offering higher bonus payments if the corresponding threshold value of $x_{\min }$ is exceeded (compare Section 4.2.2). The threshold $x_{\min }$ depicts transaction costs and is parametrized according to the power plants' remuneration classes. It is assumed that contracts for plants in lower remuneration classes have lower thresholds as they gain proportionally higher revenues (compare Section 4.2.2). Values have been derived by taking the height of the starting bonus, rounding it to an integer, and dividing it by four. The corresponding $x_{\min }$ values per remuneration class are displayed in Table 8 .

\subsection{Results}

Scenario 1. In this scenario, the height of the management premium is set according to the EEG 2012. Overall good operating results are achieved by all marketers in this case, except for the small municipal utility (see Figure 5(a)). This marketer shows a nonprofitable operation for 5 of the 6 simulated years and operates with constantly decreasing bonus payouts. The big municipal utility and the green electricity provider start with the highest operating results of about $1.2 € / \mathrm{MWH}$ and $1.8 € / \mathrm{MWh}$, respectively. Their average results show a decrease in the following years and a convergence to $0.5 € / M W h$. Both marketers increase their bonus payouts accordingly reaching a maximum of up to $2.5 € / \mathrm{MWh}$ in the last year of simulation. The operating results of startups and big utilities exhibit a slow but steady growth for the first-mentioned marketer and a nearly constant income on average for the big utilities. Both fluctuate around a profit of $0.5 € / \mathrm{MWh}$ and decrease or increase their bonus payouts over the years according to their operational results.

The specific balance energy cost (compare Figure 5(c)) of the small municipal utility is between double and triple the costs of its competitors. This cost factor does not change significantly over time and therefore poses a constant burden for the marketer.

The switch of power plant owners to other marketers offering a higher bonus payment starts after year two of the simulation. At this moment the gap between lowest and highest bonus offered is large enough to encourage plant owners with a small threshold to switch the marketing partner. The small municipal utility is the first to lose clients to the green electricity provider, as the difference of the bonus payouts is the largest between these two; see Figure 5(b). In the following years, a part of the clients of all other marketers switch to the green electricity provider as well, except for clients from the big municipal utility. Over the course of the simulation, the big utilities portfolio is reduced by about $5 \mathrm{GW}$, the one of the small municipal utility is reduced by about $2.7 \mathrm{GW}$, and the startup loses 
TABLE 7: Table representing the direct marketers' initial forecast uncertainties and capital resources.

\begin{tabular}{|c|c|c|c|c|}
\hline Direct marketer & $\sigma_{\text {price }}$ & $\sigma_{\text {power }}$ & $\mu_{\text {power }}$ & $\mathrm{M} €$ \\
\hline Big utility & 0.15 & 0.15 & 0.05 & 100 \\
\hline Municipal utility & 0.15 & 0.15 & 0.05 & 50 \\
\hline Small municipal utility & 0.25 & 0.25 & 0.15 & 20 \\
\hline Green electricity provider & 0.2 & 0.15 & 0.05 & 20 \\
\hline Startup & 0.15 & 0.2 & 0.1 & 20 \\
\hline
\end{tabular}

TABLE 8: Table representing the power plant owners' changing thresholds $x_{\min }$.

\begin{tabular}{lccc}
\hline Remuneration class & WAB [€/MWh] & PV [€/MWh] & BM [€/MWh] \\
\hline 1 & 0.5 & 0.5 & 0.5 \\
2 & 1.0 & 1.0 & 2.0 \\
3 & 1.5 & 1.5 & 1.5 \\
4 & 2.0 & 2.0 & 1.0 \\
\hline
\end{tabular}

TABLE 9: Installed capacity per remuneration class as assigned to the marketers at the beginning of simulation.

\begin{tabular}{|c|c|c|c|}
\hline Direct marketer & $\mathrm{BM}[\mathrm{MW}]$ & $\mathrm{PV}[\mathrm{MW}]$ & Wind [MW] \\
\hline \multicolumn{4}{|l|}{ Big utility } \\
\hline $\mathrm{RC} 1$ & 360 & 881 & 1648 \\
\hline $\mathrm{RC} 2$ & 22 & 567 & 5342 \\
\hline RC 3 & 125 & 29 & 5960 \\
\hline RC 4 & 15 & 220 & 1195 \\
\hline \multicolumn{4}{|l|}{ Municipal utility } \\
\hline $\mathrm{RC} 1$ & 719 & 1761 & 1030 \\
\hline $\mathrm{RC} 2$ & 45 & 1134 & 3339 \\
\hline $\mathrm{RC} 3$ & 125 & 59 & 3725 \\
\hline $\mathrm{RC} 4$ & 15 & 440 & 398 \\
\hline \multicolumn{4}{|c|}{ Small municipal utility } \\
\hline $\mathrm{RC} 1$ & 240 & 1761 & 206 \\
\hline $\mathrm{RC} 2$ & 15 & 1134 & 668 \\
\hline RC 3 & 125 & 59 & 745 \\
\hline RC 4 & 15 & 440 & - \\
\hline \multicolumn{4}{|c|}{ Green electricity provider } \\
\hline $\mathrm{RC} 1$ & 479 & 881 & 412 \\
\hline $\mathrm{RC} 2$ & 30 & 567 & 1336 \\
\hline RC 3 & 375 & 29 & 1490 \\
\hline RC 4 & 46 & 220 & - \\
\hline \multicolumn{4}{|l|}{ Startup } \\
\hline $\mathrm{RC} 1$ & 599 & 12329 & 824 \\
\hline RC 2 & 37 & 7940 & 2671 \\
\hline RC 3 & 1750 & 412 & 2980 \\
\hline RC 4 & 216 & 3077 & 398 \\
\hline
\end{tabular}

about $2 \mathrm{GW}$. The sum of them is added to the portfolio of the green electricity provider doubling its portfolio size; see Figure $7(\mathrm{a})$.

Scenario 2. In the scenario with a $50 \%$ reduced management premium for VRE, the simulation shows a different development of the marketers business success as can be seen in Figure 6. The "big municipal utility" and green electricity provider start with positive operating results; the other marketers' results are negative. Whereas the green electricity provider can assure his income throughout the simulation and increases his bonus payouts, the "big municipal utility" earns about $0.5 € / \mathrm{MWh}$ until year four hardly changing the bonus. In this year the gap between own bonus payouts and the highest payouts of the green electricity provider is large enough to lose wind and biomass power plants. The loss of biomass plants especially reduces the high profitable income from the reserve market and, accordingly, the bonus 


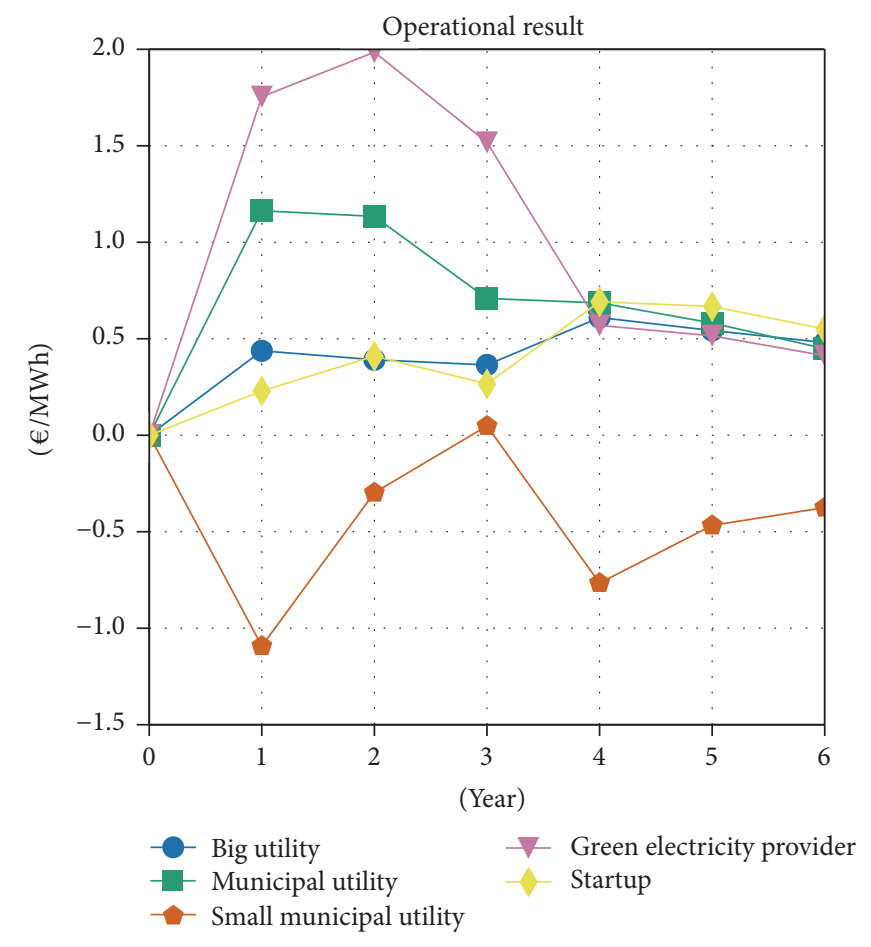

(a)

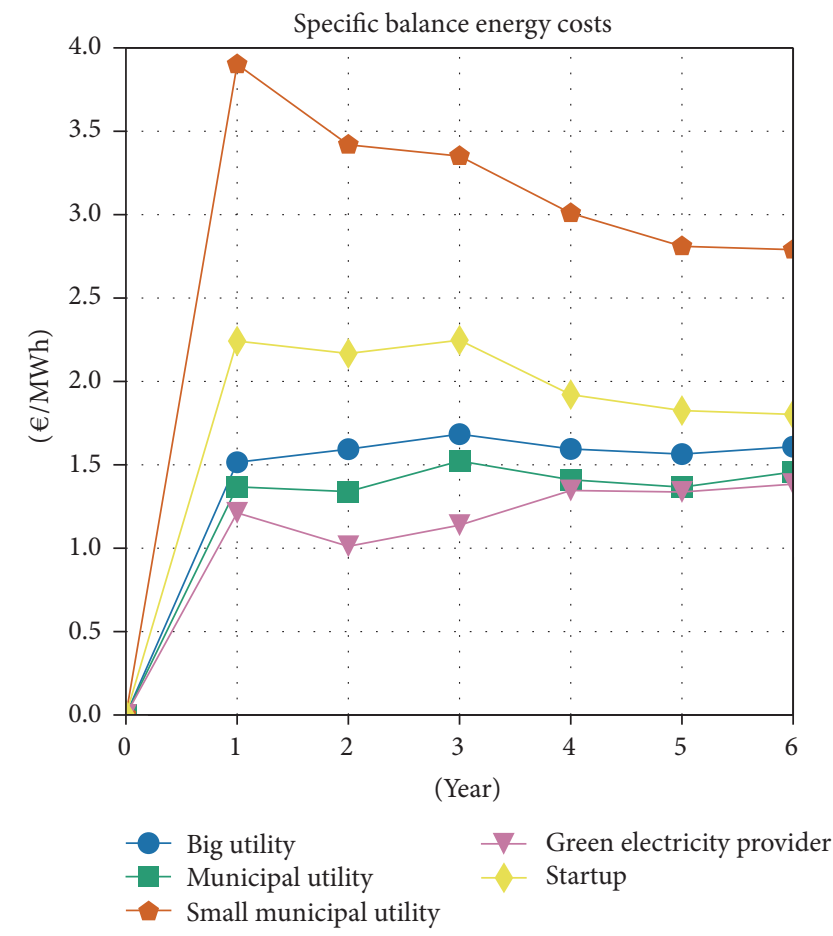

(c)

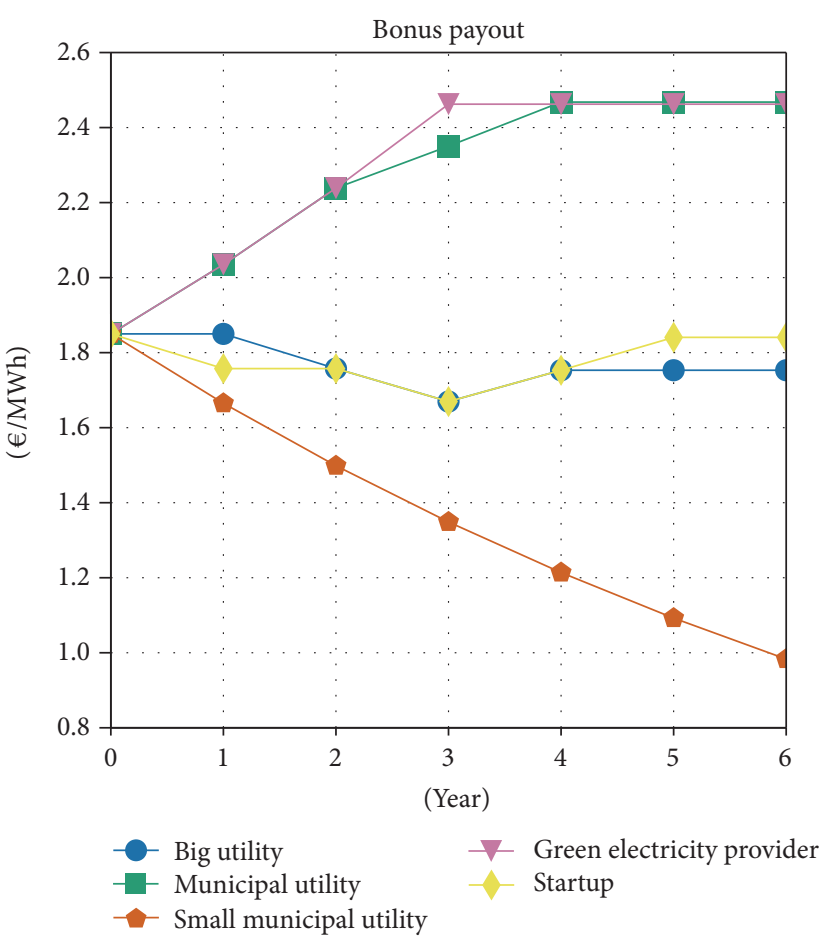

(b)

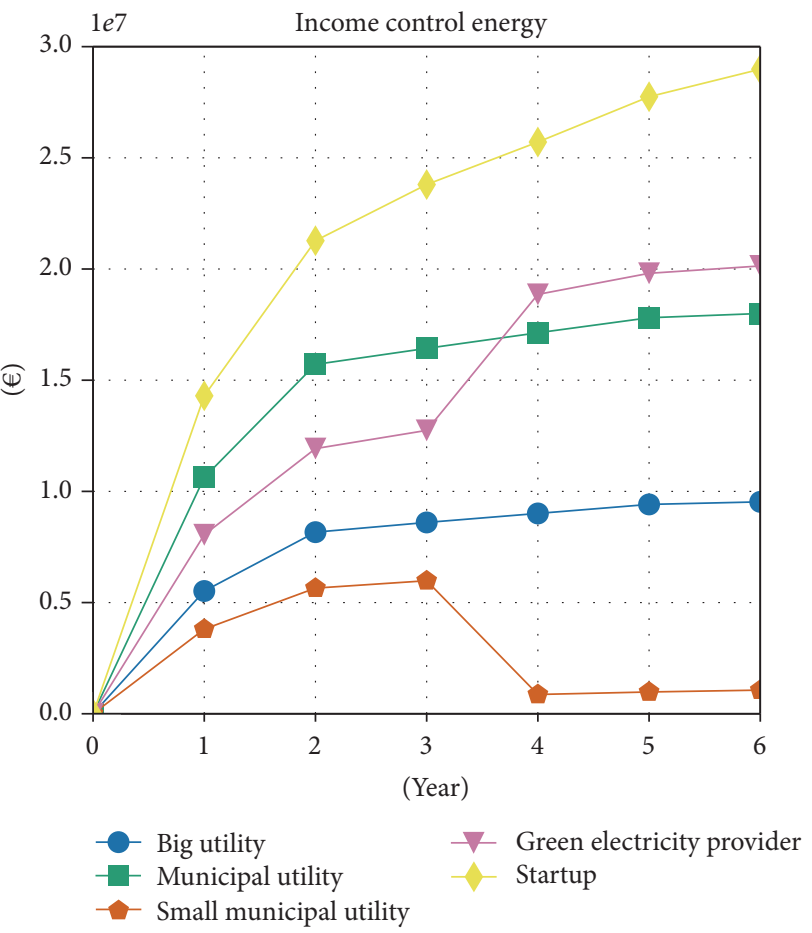

(d)

FIGURE 5: Specific operational results, bonus payouts, balance energy costs, and income from the control energy market for all 5 marketers in the first scenario.

is reduced in the following years with negative results of about $-0.8 € / \mathrm{MWh}$.

The startup has an operational result of just below zero, depletes all its available capital until the fourth year, and reduces its bonus payout to $0 € / \mathrm{MWh}$. Already after the second year, the bonus difference to the green electricity provider is too large, losing a part of its biomass power plants to this competitor. Accordingly, the income of the reserve 


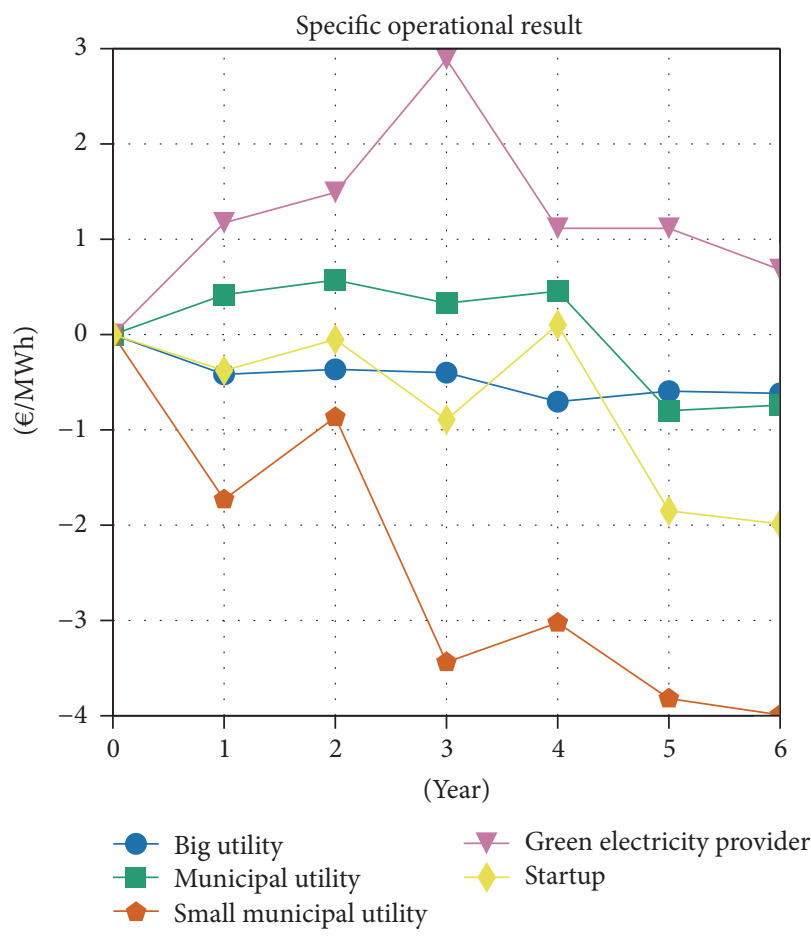

(a)

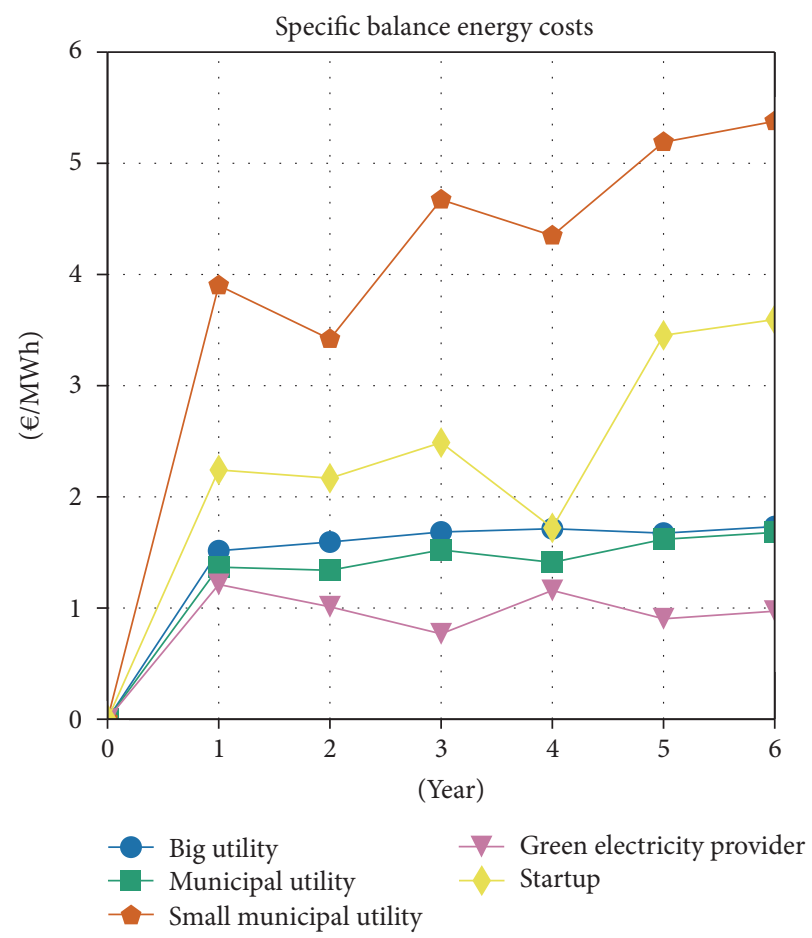

(c)

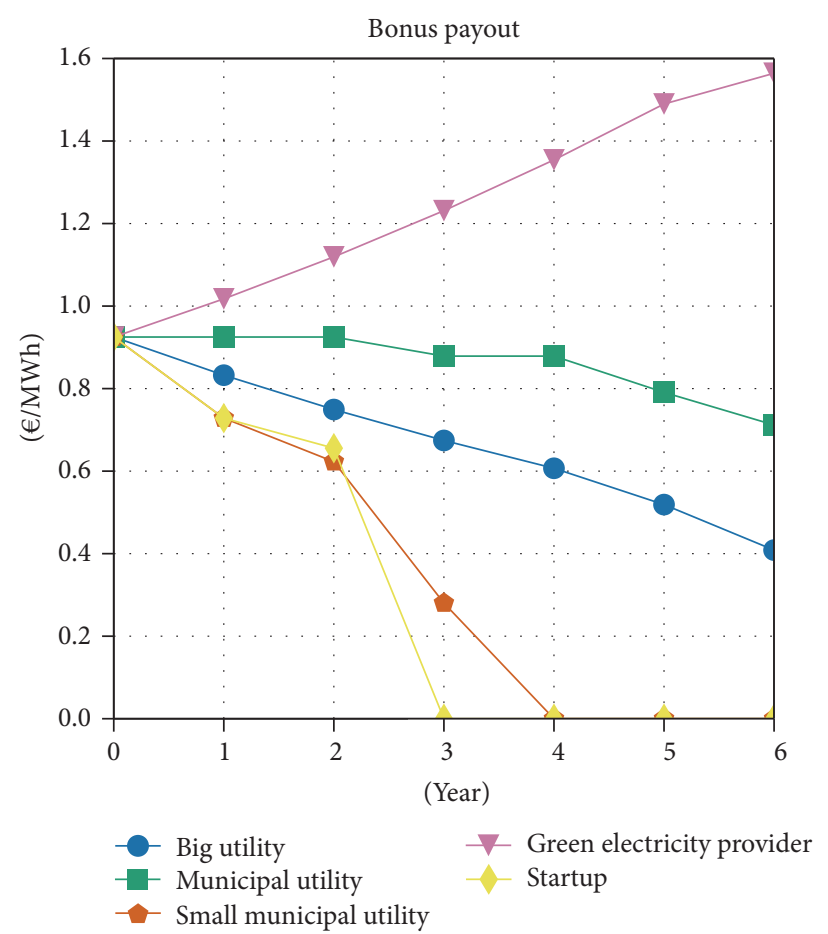

(b)

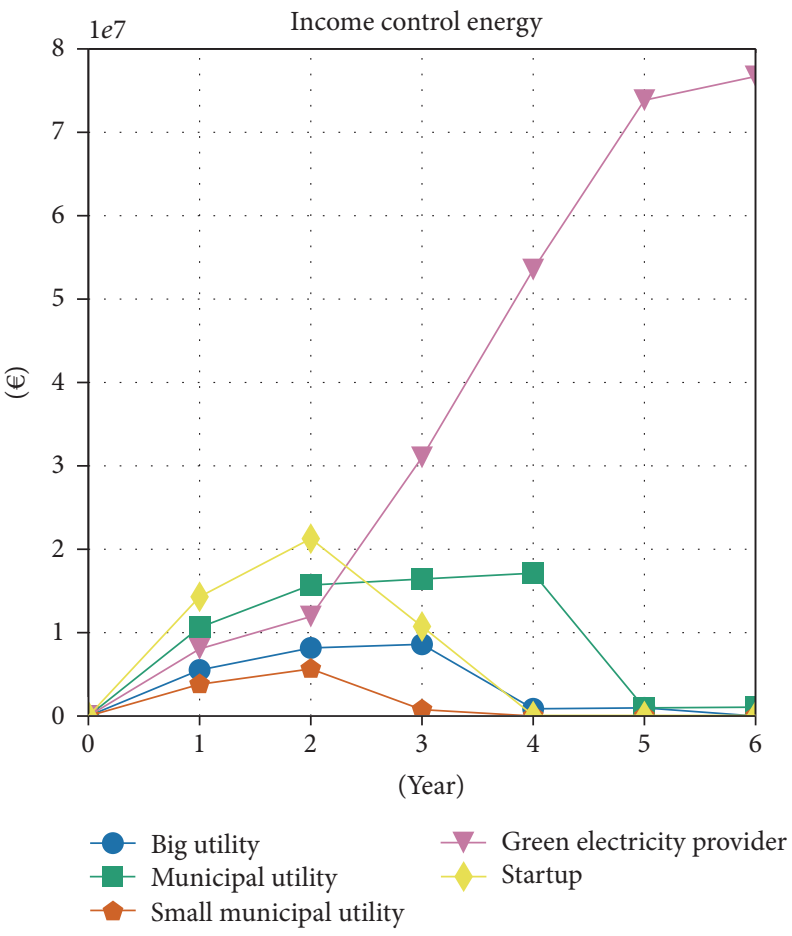

(d)

FIGURE 6: Specific operational results, bonus payouts, balance energy costs, and income from the control energy market for all 5 marketers in the second scenario with reduced management premium.

market decreases while the cost for balance energy increases. The specific operational result drops to about $-1 € / \mathrm{MWh}$ in year three. The capital of the startup is used up and bonus payments are stopped. Biomass, wind, and photovoltaic power plant operators switch to the green electricity provider that offers the highest bonus payouts. The new portfolio implies a reduction of balance energy costs leading to a positive operational result in year four. Yet the capital stock remains 

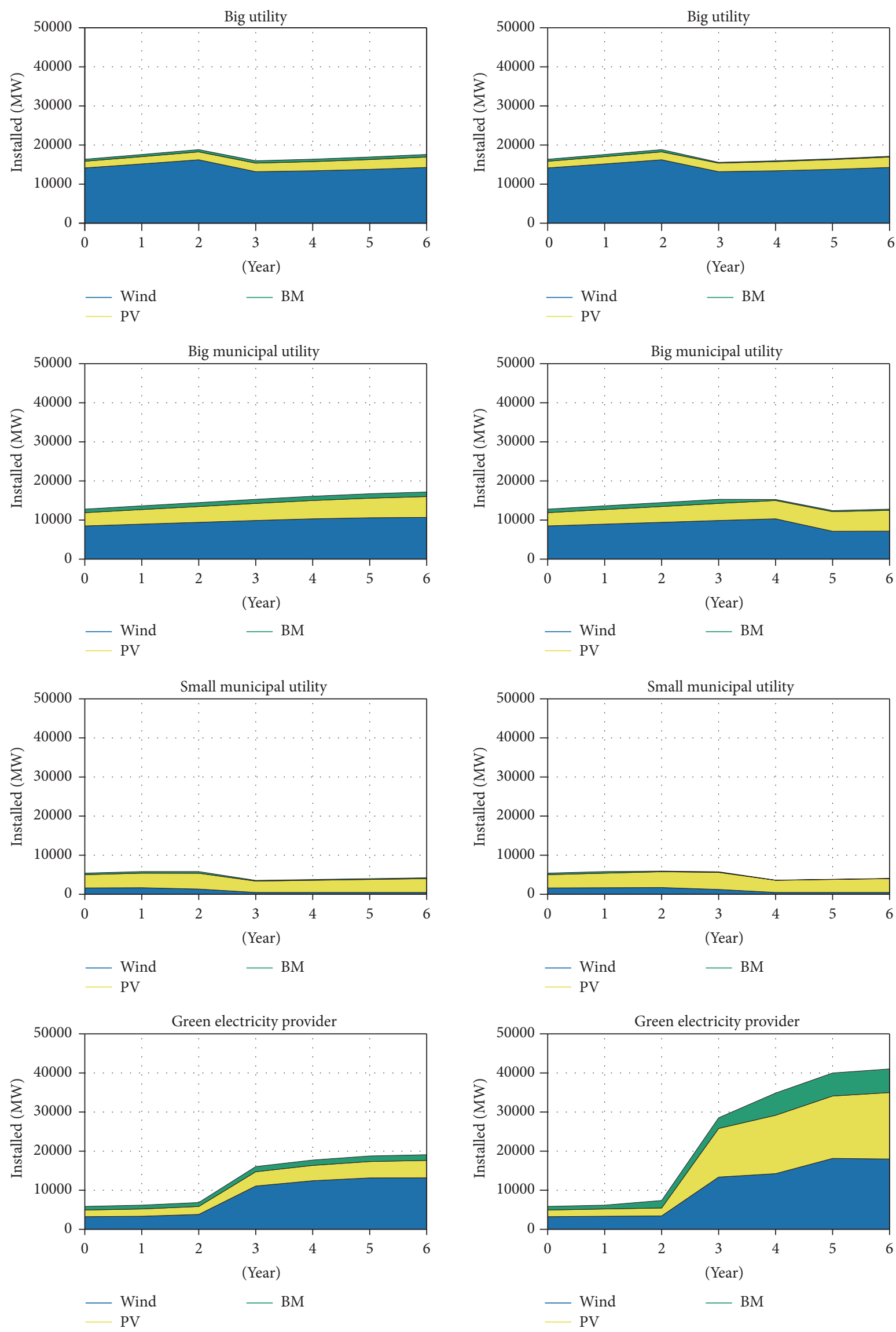

FIgURe 7: Continued. 


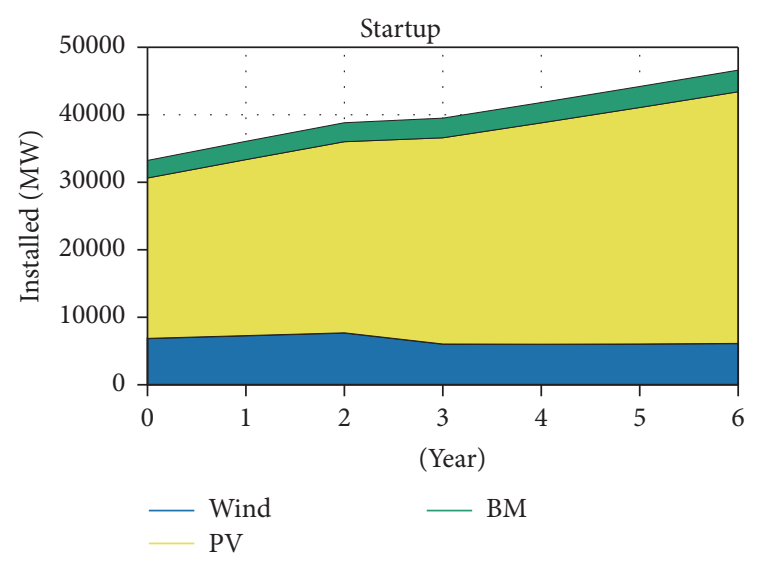

(a)

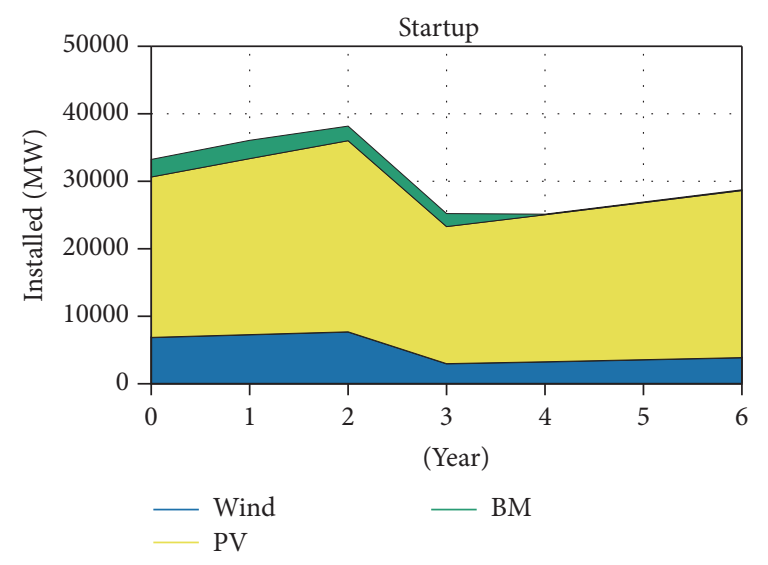

(b)

FIgURE 7: Evolution of the marketers' portfolios for Scenario 1 (a) and Scenario 2 (b).

negative and bonus payouts are still ceased. A large fraction of the remaining biomass plants leave the startup, resulting in increased balance energy costs and negative operational results of up to $-2 € / \mathrm{MWh}$ in the following years.

With an operational result of about $-0.6 € / \mathrm{MWh}$ over the years, the big utility gradually reduces its bonus payout without hardly any effect on its results. The only slow decrease of bonus is due to the operational result to capital ratio; compare Table 3 and Figure 8. The small municipal utility loses money for every MWh produced. On average, this marketer is losing every year $0.6 € / \mathrm{MWh}$ more than in the previous year. After the fourth year, it stops bonus payouts and most of its portfolio's wind and biomass plants switch to another marketer. At the end of simulation, it is the green electricity provider that increases its portfolio by about 4.5 GW from the big utility, 3.5 GW from "big municipal utility," $3 \mathrm{GW}$ from small municipal utility, and $17 \mathrm{GW}$ from the startup, Figure 7(b).

\section{Discussion}

6.1. Discussion of Case Study Results. The case study reveals valuable insights concerning the income and portfolio dynamics of different RES-E marketer actor classes. Scenario 1 shows that incumbent marketers such as big utilities that focus on a large wind power portfolio-share can benefit due to economies of scale from lower specific operational costs and better forecast qualities. On absolute levels, their economic success is among the best (see Figures 8 and 9). However, we also identify a mediating disutility of scale. As described earlier, marketers can profit by trading electricity on different electricity markets, namely, the wholesale power market and the negative minute reserve market. Yet, only the electricity of biomass plants has been allowed to participate in the control power market in the model (since 2017 also wind power plant operators are allowed to bid firm capacity on the control power market if certain prequalifying conditions are fulfilled in a pilot phase). Trading electricity of these controllable plants implies less balancing costs and improves overall operational results. The access to this dispatchable resource is limited and unevenly distributed among the marketers' portfolios. However, the actors analysis revealed that upcoming small marketers often have better access to biomass PPOs through personal connections to local farmers and thus comparatively more biomass contracted in their portfolio. Having access to this dispatchable energy source can mitigate the disadvantages of small portfolio sizes. In combination with an adequate forecast quality, this can lead to financially successful marketing of RES-E, as the results of the green electricity provider depict, allowing a niche of new market entrants to survive next to incumbent marketers.

Additionally, the model allows the investigation of how the market structure changes if marketers are enabled to compete for new PPOs to complement their portfolio. The bonus payout follows a simple adjustment rule: the higher the operational result is, the higher the bonus marketers pay to their contracted PPOs. This leads to a convergence towards a common specific operational result for all marketers in Scenario 1 (except for the small municipal utility) and ensures a strong competition concerning the bonus payout and the attraction of new PPOs. In this scenario, the bonus adjustments and the contract switches of PPOs to other marketers are only moderately dynamic. Comparatively small gaps between bonus heights arise, and plant capacities of only about $10 \mathrm{GW}$ in total switch marketers. Except for the small municipal utility, the system stabilizes to a state in which four successful marketers coexist.

Slight changes in the regulatory framework (a reduction of the management premium for VRE) lead to completely changed income and portfolio dynamics; compare Figures 10 and 11. In Scenario 2, only one marketer manages to trade the electricity profitably and to increase bonus heights. All other marketers have to decrease their bonus payouts and thus a large difference in payouts exists between the marketers even in an early stage of simulation. Startups, for example, struggle in the first four years with their operational result just below zero. During this time, they reduce the bonus height to be profitable. In year four, the startup manages to have a positive result but at the same time its bonus payouts ceased and a large difference in bonus height to 

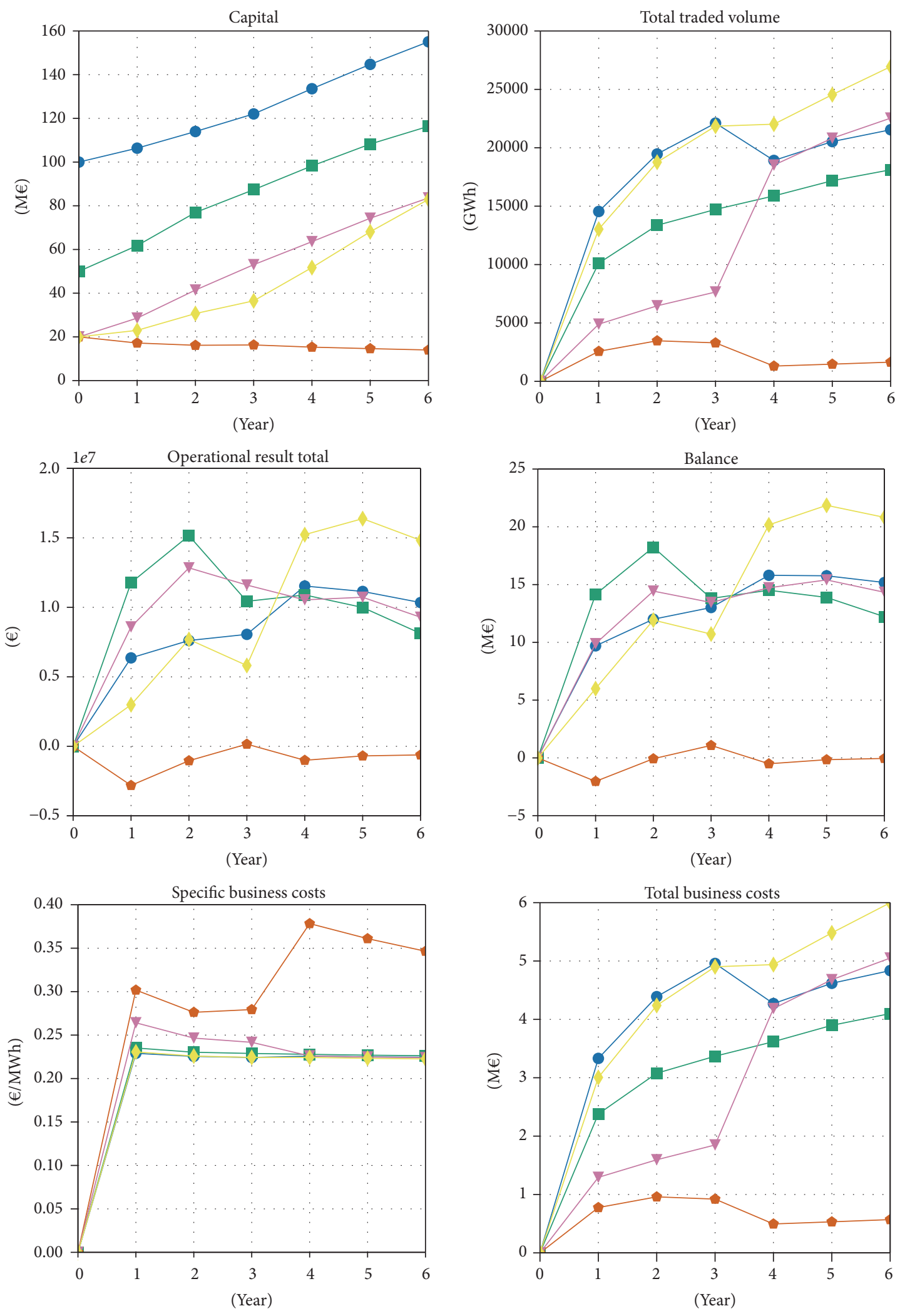

Big utility

Municipal utility

Small municipal utility

Green electricity provider

Startup

Big utility

Municipal utility

Small municipal utility

$\nabla$ - Green electricity provider

- Startup

FIGURE 8: Scenario 1 results. The balance reflects all income and expenses at the market, including payments for balance energy, excluding the business costs. Business costs are considered in the operational result. 

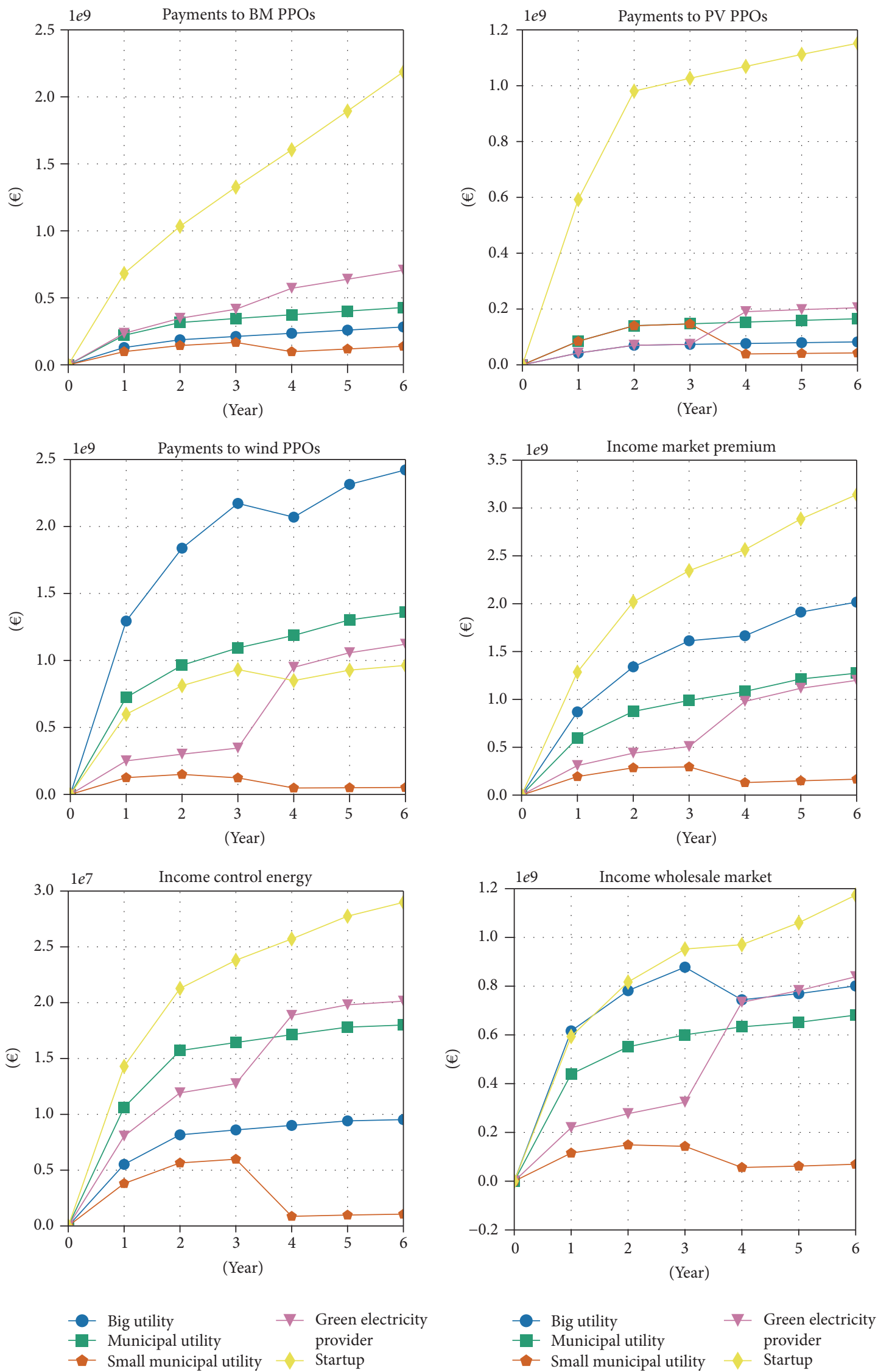

Figure 9: Scenario 1 results. Income and expenses of the marketers. 

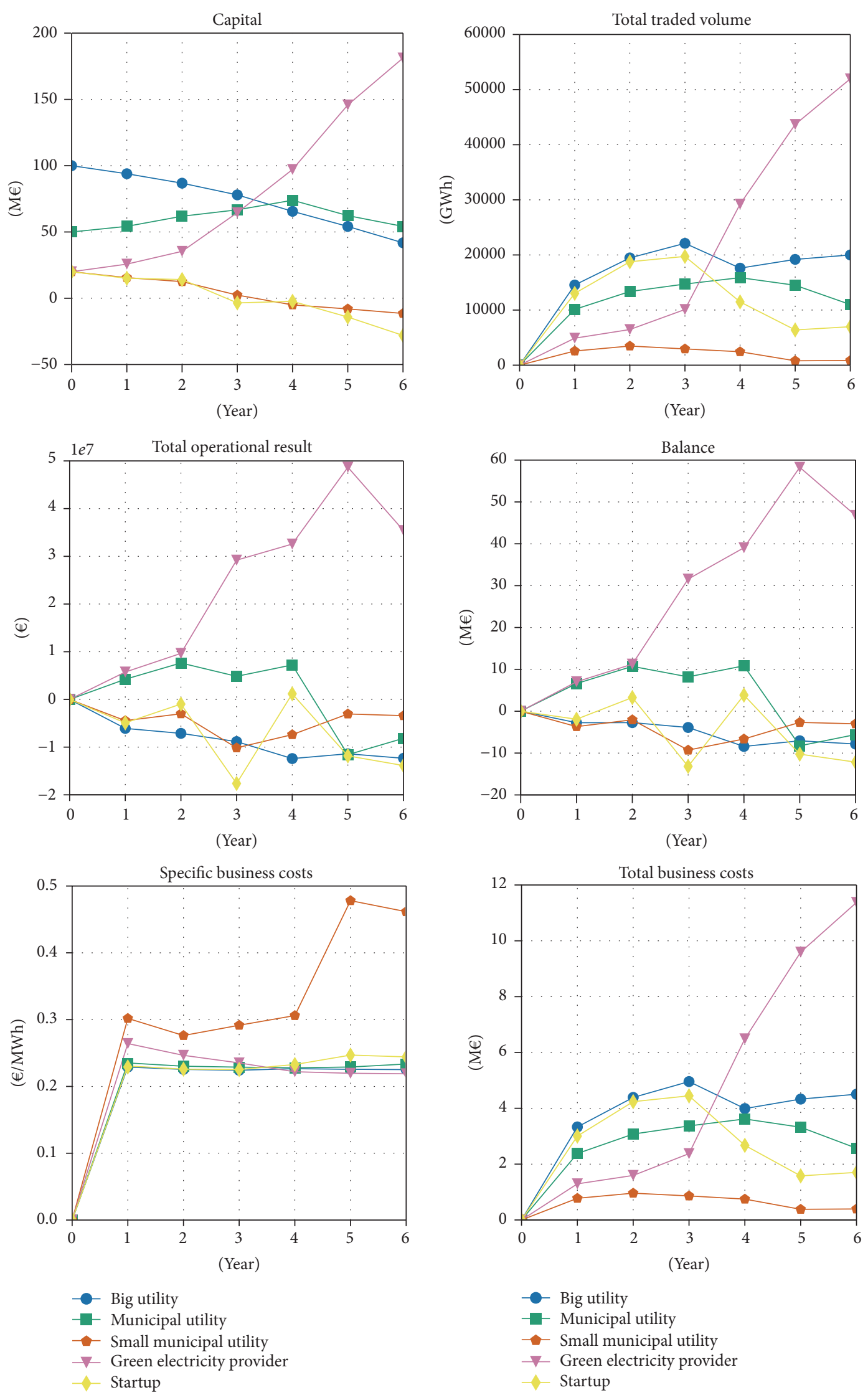

FIGURE 10: Scenario 2 results. The balance reflects all income and expenses at the market, including payments for balance energy and excluding the business costs. Business costs are considered in the operational result. 

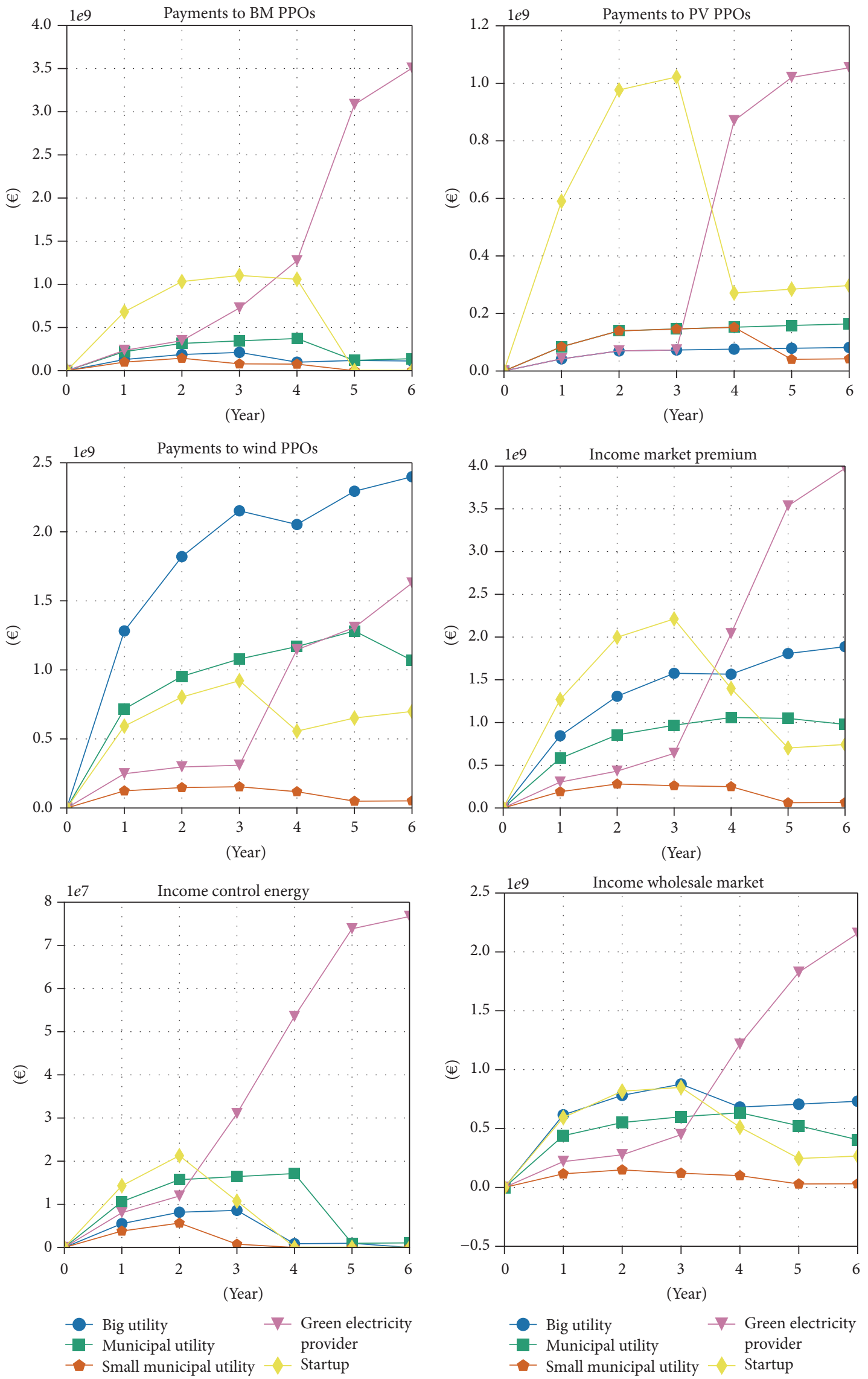

FIGURE 11: Scenario 2 results. Income and expenses of the marketers. 
the other marketers has emerged. Even with a well balanced portfolio with a relatively large share of biomass plants, they cannot offer bonus payouts and lose the biomass plants to competitors. With the remaining variable renewables in their portfolio and forecasts of minor quality, it is impossible for the startup to trade profitably.

Clearly, the observed effect of a changed management premium depends on the initial parametrization of the studied marketers as well as on the behaviour of the power plant owners. It is therefore important that an rigorous and profound actors analysis is performed to gain parameter values from empirical actors data. A relative comparison between two scenario variants as presented here should be uncritical, however. The question of parameter choice is discussed in the upcoming subsection.

6.2. Model Outlook: Overcoming Current Weaknesses. In agent-based modelling, the complexity of the modelled systems inevitably hampers the reporting of results as well as the policy advice. However, for some years now, attempts have been made to establish standards for the model description [57], model calibration and validation [58], and the setting up of simulation experiments [59].

In this line of reasoning, some of the used parameter assumptions should be systematically elaborated in further studies. Only an automated sensitivity analysis of a broad set of parameters would offer the required confidence intervals for a comprehensive quantitative evaluation. For example, the setting of a starting bonus for all marketers is not very realistic. Starting conditions should be adapted to the actors according to their capabilities in order to avoid skewed results in the beginning of the simulation. The threshold parameter $x_{x \min }$ and the capital of the marketers can only be based on educated guesses so far. Individual decisions and confidentiality limit the information flow in these cases.

Likewise, the decision-making of actors has to be studied and implemented with sufficient accuracy. The presented bonus adjustment rules are grounded on the assumption that marketers aim for an operational result of $0.5 € / \mathrm{MWh}$ (stated as "typical margin" in power trading in general in the interviews) and adapt the bonus payouts according to the budgetary surplus. An alternative approach would assign different goals for the operational results to different marketers. However, it would be hard to estimate the marketers aim for the operational results individually as those numbers would be handled confidentially in real-world examples in most cases. An even more sophisticated approach would optimize the marketer's profit in dependence on the choice of bonus height.

Improvements of the presented bonus adjustment rules would certainly address the current myopic decision rules, as they are only based on operational results and the capital of the last year. Additional learning from previous years would improve the adoption of decision thresholds.

In general, the adaptability of AMIRIS' agents-how they change behaviours during the simulation-needs to be enhanced. In this context, an important development goal is the model endogenous expansion of installed RES-E capacity. This would allow for an estimation of the possible height of incentives to reach certain deployment goals and to study potential barriers for RES-E investments. Developments for this are currently carried out.

Further model enhancements consider the use of flexibility options, the analysis of the demand side, and the modelling of additional support mechanisms. This way, further relevant dimensions in the future energy system's complexity are represented.

Besides the use as a standalone model, AMIRIS may complement studies done with traditional energy system optimization models in order to enhance insights for the electricity system transformation from a market-based perspective (for a recent example, see, e.g., [60]). This way, the so-called "efficiency gap" between optimal and real market outcomes could be analysed. Additionally, conclusions might be drawn from such complementary studies about why decisions of heterogeneous actors on the microlevel might not necessarily result in a cost-optimal system configuration at the macrolevel and likewise on necessary policy instruments design to achieve a cost-optimal system configuration.

6.3. Lessons Learned Using an Agent-Based Model Approach. In a recent study, Macal presented a classification of agent-based modelling approaches, namely, individual, autonomous, interactive, and adaptive ABMs, in increasing order of sophistication [61]. In adaptive ABMs, agents change behaviours during the simulation. In comparison, an interactive agent-based model offers individuality of the agents with a diverse set of characteristics, endogenous and autonomous behaviours, and direct interactions between agents and the environment [61]. AMIRIS falls under the interactive category. The agents are modelled with particular scopes in decision-making, for example, the marketers' decisions regarding the adjustment of bonuses. The agents' interactions such as the one between marketer and plant operator or between marketer and market determine their success on the microlevel of actors. Nevertheless, agents do not change behaviours during simulation.

For the purpose of the model, however, this adaptability is not necessary in order to study complex system interrelations. With the case study, we present evidence for the existence of economic niches that arise for smaller, upcoming marketers and which can prevent a market concentration towards the biggest marketers with best forecast qualities and lowest specific operational incomes. We thus show that specific agent attributes like portfolio composition and size are decisive for the evolutionary economic success of marketers. This shows that sophisticated behavioural modelling is not always necessary in an ABM to make claims about emergent phenomena in systems and the complexity of agent interactions. Likewise, it would be hard to gain these insights about portfolio effects from other simulation methods but ABM.

The modelled market modules have been validated with classical "history friendly" methods (compare [10]). Results of AMIRIS depend on the interplay between several implemented modules generating a macrooutcome that remains hard to validate due to missing empirical data about market structure developments. Therefore, model results are to be interpreted as possible and plausible tendencies of the system 
development-an interpretation that is suitable for most models with explorative character including ABMs.

AMIRIS allows importing changes in the regulatory framework as input parameters for explorative scenarios, considering that no normative system targets are to be achieved by individual actors. Specific policy interventions can be dynamically traced in the model. According to the classification of intervention modelling carried out by Chappin [62], this level should be aimed for when assessing interventions in a model context. In this way, our approach allows examining the impact of policy instruments considering the complex interplay between the regulatory framework, the actors, and the technoeconomic regime (see also Figure 1).

\section{Conclusion}

The agent-based model AMIRIS has been developed in order to analyse the impact of policy instruments regulating renewable energy market integration. The model depicts the electricity system as a complex sociotechnical system and focuses on the interdependencies between the regulatory framework, actors, and markets. The model contributes to the scientific literature in several ways.

AMIRIS offers configurations of scenarios under different external input parameters like RES-E policy support mechanisms. While there are other energy related ABMs that explore the impact of policy instruments on energy markets (see, e.g., $[42,43]$ ), the focus on RES-E in a high temporal resolution and the typecast of actor groups is unique in the field of energy systems analysis to our best knowledge.

Different agent specifications enable defining the degree of uncertainty and bounded rationality of the actors and modelling heterogeneous system entities. Marketers especially can be defined in detail by specifying, for example, their portfolios and cost structures and their capitalization and forecast uncertainties. The specification of agents is crucial for the right interpretation of simulation results, so actor analyses have been conducted prior to model implementation and simulations. The gained insights from such analyses are used to map agent decision rules and to characterize the actors and to configure corresponding parameters in AMIRIS. It is shown that many market dynamics can be unraveled if heterogeneous agent attributes are taken into consideration.

The case study demonstrated how only minor policy changes can have a considerable effect on the agent population. This indicates how well-prepared and parametrized a transition of regulatory framework conditions has to be in order to further ensure the functioning of the system and the survival of particular actor classes. In Scenario 2, for example, the economic survival of the startup and further marketers might have been possible in case the regulatory framework would have been changed by more circumspect planning. We thus show that the intermediary market actors have to be considered in case amendments of RES-E policy instruments are planned as new interdependencies between plant operators and marketers arise.

Niches play a vital role in innovation formation in sociotechnical systems and are a fundamental driver of system transition [63]. With AMIRIS, the emergence and stability of energy market niches can be depicted without prior knowledge about their prospect of success. Their economic success would be hard to identify and trace in other, more traditional modes of simulation. The model is thus also business relevant if the results are viewed from an actors perspective. For instance, the case study revealed that competition and related changes of actors' portfolios may lead to bankruptcy of otherwise successful marketers.

To sum up, the paper demonstrates that agent-based models are suitable in multiple dimensions to study the dynamics of electricity systems under transition which are driven by a diverse set of heterogeneous actors. While there is still many open development goals (see Section 6.2), we do not regard any of these issues raised as a fundamental concern impossible to overcome.

Studying the energy system transition demands methods that are able to capture the system's complexity and dynamics. An important property of $\mathrm{ABM}$ approaches is their ability to flexibly use models in the model, enabling the researcher to represent the system in multiple layers. We conclude that agent-based modelling approaches like AMIRIS have the ability to enhance the knowledge that is required to ensure a successful energy system transition while preventing system breakages.

\section{Appendix}

The revenue calculation is described in detail in the following section. Revenue can be generated at the wholesale (XM) and control energy market (CE); balancing energy (bal) can add to the revenue if circumstances are favourable. The total revenue is given by

$$
i(t)=i_{\mathrm{XM}}(t)+i_{\mathrm{CE}}(t)+i_{\text {bal }}(t) .
$$

The sold volume $V_{\mathrm{XM}}(t)$ traded at the power exchange market is refunded with the management premium $M(t)$ and allows earnings of

$$
i_{\mathrm{XM}}(t)=V_{\mathrm{XM}}(t) \cdot\left(\Pi_{\mathrm{XM}}(t)+M(t)\right),
$$

with the wholesale power market price $\Pi_{\mathrm{XM}}(t)$. Likewise, revenues from the control energy market equate to

$$
i_{\mathrm{CE}}(t)=V_{\mathrm{CE}}(t) \cdot \Pi_{\mathrm{CE}}(t) .
$$

The revenue from balancing energy equals negative balancing costs of the marketer; that is,

$$
i_{\text {bal }}(t)=-c_{\text {bal }}(t) .
$$

The fix costs are calculated as

$$
c_{\mathrm{fix}}=c_{\mathrm{IT}}+c_{\text {trade, fix }} .
$$

Variable costs equate to

$$
\begin{aligned}
c_{\text {var }}(t)= & c_{\mathrm{XM}, \text { trading }}(t)+c_{\text {pers,var }}(t)+c_{\text {bal }}(t) \\
& +c_{\mathrm{fcst}}(t)+c_{\text {bonus }}(t) .
\end{aligned}
$$


Trading costs are based on the fees at the exchange market for every traded MWh with

$$
c_{\mathrm{XM}, \text { trading }}(t)=c_{\text {trade,var }} \cdot V(t) .
$$

In case balancing energy is required, the corresponding volume $V_{\mathrm{bal}}(t)$ must be procured for a price $\mathrm{PR}_{\mathrm{bal}}$ and costs are defined as

$$
c_{\mathrm{bal}}(t)=\mathrm{PR}_{\mathrm{bal}} \cdot V_{\mathrm{bal}}(t) .
$$

According to the actors analysis the prices $\mathrm{PR}_{\mathrm{fcst}}$ per $\mathrm{MW}$ typically decrease with larger portfolio sizes, so

$$
c_{\mathrm{fcst}}(t)=c_{\mathrm{fcst}}(\mathscr{P}) \cdot \mathscr{P}(t) .
$$

The size of $V_{\mathrm{bal}}(t)$ is the difference between the real actual $V(t)$ and the forecast $V_{\text {fcst }}(t)$ electricity feed-in at time $t$ :

$$
V_{\mathrm{bal}}(t)=V(t)-V_{\mathrm{fcst}}(t)
$$

where the latter has been forecast by the marketer $24 h$ before and is determined by

$$
\begin{aligned}
V_{\mathrm{fcst}}(t+24 \mathrm{~h})= & V(t+24 \mathrm{~h}) \\
& \cdot\left(1+\mu_{\text {power }}+\sigma_{\text {power }} \cdot g\right),
\end{aligned}
$$

with $g$ representing a random variable from a normal distribution. $V(t+24 \mathrm{~h})$ denotes the actual feed-in volume $24 \mathrm{~h}$ ahead. The revenue of the RES operator agents is based on the remuneration and the bonus payments from the direct marketer; that is,

$$
i(t)=V_{\mathrm{el}} \cdot\left(\Pi_{\mathrm{rc}}(t)+i_{\text {bonus }}(t)\right) .
$$

The Market Premium. The aim of the market premium under the EEG is to integrate renewable energy sources into the energy market system by fostering direct marketing. Producers receive a financial compensation for the difference between energy-source-specific values to be applied (replacing the fixed feed-in tariff) as a calculation basis and the market value. This is the average energy-source-specific monthly value of the hourly contracts on the spot market for electricity (Part 3, Division 1 and Annex 1 EEG 2017). Compensating for occurring costs from direct marketing the values to be applied are higher than the replaced feed-in tariffs. The difference is set to $2 € / \mathrm{MWh}$ for dispatchable renewables and $4 € / \mathrm{MWh}$ for intermittent renewables (Section 53 EEG 2017). Under EEG 2012 such a difference has been separately disclosed as a management premium (Section 33g EEG 2012).

\section{Conflicts of Interest}

The authors declare that there are no conflicts of interest regarding the publication of this article.

\section{Acknowledgments}

The authors are grateful to Wolfram Krewitt who originally conceived the development of an agent-based simulation model for the analysis of the market integration of renewables. They would also like to show their gratitude to Ulrich Frey, Benjamin Fuchs, Eva Hauser, Wolfgang Hauser, Thomas Kast, Uwe Klann, Uwe Leprich, Tobias Naegler, Nils Roloff, Christoph Schimeczek, Yvonne Scholz, Bernd Schmidt, Sandra Wassermann, Rudolf Weeber, and Wolfgang WeimerJehle for their expert advice and contributions to the development of AMIRIS. They are thankful to all colleagues of their department for numerous fruitful discussions on AMIRIS's development and application. For the recent and ongoing funding they are much obliged to the German Ministry for the Environment, the German Ministry for Economic Affairs, the German Ministry for Research, and internal funding by the DLR within several research projects (Grant nos. BMU FKZ 0325015, BMU FKZ 0325182, BMWi FKZ 03ET4020A, BMWi FKZ 03SIN108, BMWi FKZ 03ET4032B, BMWi FKZ 03ET4025B, and BMBF FKZ 03SFK4D1).

\section{References}

[1] IPCC, Mitigation of Climate Change. Contribution of Working Group III to the Fifth Assessment Report of the Intergovernmental Panel on Climate Change. Summary for Policymakers, Cambridge University Press, Cambridge, UK, 2014.

[2] IEA, “World Energy Outlook 2015," Digestive Endoscopy, 2015, http://dx.doi.org/10.1787/weo-2015-en.

[3] REN21, Renewables 2016 Global Status Report, REN21 Secretariat, Paris, 2016, http://www.ren21.net/GSR-2016-ReportFull-report-EN.

[4] J. Scheffler, "Gesetz für den Vorrang Erneuerbarer Energien - EEG," in Die gesetzliche Basis und Förderinstrumente der Energiewende, essentials, pp. 5-31, Springer Fachmedien Wiesbaden, Wiesbaden, 2014.

[5] J. Scheffler, "Gesetz für den Vorrang Erneuerbarer Energien - EEG," in Die gesetzliche Basis und Förderinstrumente der Energiewende, essentials, pp. 5-31, Springer Fachmedien Wiesbaden, Wiesbaden, 2000.

[6] U. Büsgen and W. Dürrschmidt, "The expansion of electricity generation from renewable energies in Germany," Energy Policy, vol. 37, no. 7, pp. 2536-2545, 2009, http://dx.doi.org/10.1016/ j.enpol.2008.10.048.

[7] EEG, "Gesetz für den Vorrang Erneuerbarer Energien (Erneuerbare-Energien-Gesetz)," 2012, https://www.erneuerbare-energien.de/EE/Redaktion/DE/Gesetze-Verordnungen/eeg_2012_ bf.html.

[8] M. Klobasa, M. Ragwitz, F. Sensfuß et al., "Nutzenwirkung der Marktprämie," Working Paper Sustainability and Innovation No. S 1/2013, Fraunhofer Institut für System- und Innovationsforschung ISI.

[9] Federal Ministry for Economic Affairs, "Energy, Renewable Energy Sources in Figures," National and International Development, 2014.

[10] R. Matthias, K. Nienhaus, N. Roloff et al., "Weiterentwicklung eines agentenbasierten Simulationsmodells (AMIRIS) zur Untersuchung des Akteursverhaltens bei der Marktintegration von Strom aus erneuerbaren Energien unter verschiedenen Fördermechanismen," Deutsches Zentrum für Luft- und Raumfahrt e.V. (DLR), 2013, http://elib.dlr.de/82808/.

[11] R. Schemm and B. Daniel, "Make oder Buy," Erneuerbare Energien, vol. 10, no. 2014, pp. 40-43, 2014. 
[12] A. Grunwald, "Energy futures: Diversity and the need for assessment," Futures, vol. 43, no. 8, pp. 820-830, 2011, http://dx.doi .org/10.1016/j.futures.2011.05.024.

[13] C. S. Bale, L. Varga, and T. J. Foxon, "Energy and complexity: New ways forward," Applied Energy, vol. 138, pp. 150-159, 2015.

[14] L. Tesfatsion, "Chapter 16 Agent-Based Computational Economics: A Constructive Approach to Economic Theory," Handbook of Computational Economics, vol. 2, pp. 831-880, 2006.

[15] EEX, "EEX Spot-price data from the year 2011," https://www.eex .com/de/marktdaten/strom/spotmarkt.

[16] ENTSO-E, "ENTSO-E load and consumption data," https:// www.entsoe.eu/db-query/consumption/monthly-consumption-of-a-specific-country-for-a-specific-range-of-time.

[17] L. Matthias and L. Annette, “The 2014 German Renewable Energy Sources Act revision - from feed-in tariffs to direct marketing to competitive bidding," Journal of Energy and Natural Resources Law, vol. 33, no. 2, pp. 131-146, 2015, http://dx.doi.org/ 10.1080/02646811.2015.1022439.

[18] D. Kahneman, Thinking, Fast and Slow, Penguin Books, London, UK, 2011.

[19] A. Tversky and D. Kahneman, "Judgent Under Uncertainty: Heuristics and Biases," Science, vol. 185, pp. 1124-1131, 1974.

[20] W. Brian Arthur, "Inductive Reasoning and Bounded Rationality," The American Economic Review, vol. 84, no. 2, pp. 406-411, 1994, http://www.jstor.org/stable/2117868.

[21] M. G. De Giorgi, A. Ficarella, and M. Tarantino, "Error analysis of short term wind power prediction models," Applied Energy, vol. 88, no. 4, pp. 1298-1311, 2011.

[22] M. Lange, Analysis for the Uncertainty of Wind Power Prediction, [Ph.D. thesis], Carl von Ossietzky University of Oldenburg, Germany, 2003.

[23] S. Rentzing, "Im Schatten der Photovoltaik," Neue Energie, vol. 10 , pp. 48-51, 2011.

[24] O. Tietjen, Analyses of Risk Factors in Conventional and Renewable Energy Dominated Electricity Markets, [Ph.D. thesis], Masterarbeit an der Freien Universiterlin (FU) und Potsdam Institute for Climate Impact Research (PIK), 2014.

[25] A. Weidlich, Engineering Interrelated Electricity Markets - An agentbased computational Approach [Ph.D. thesis], Disseration - Universitat Karlsruhe TH - Faculty of Economics, 2008.

[26] G. Gallo, "Electricity market games: How agent-based modeling can help under high penetrations of variable generation," The Electricity Journal, vol. 29, no. 2, pp. 39-46, 2016, http://dx.doi.org/10.1016/j.tej.2016.02.001.

[27] B. Wooldrige, An Introduction to Multi-Agent Systems, John Wiley and Sons, Chichester, UK, 2002.

[28] C. M. MacAl and M. J. North, "Tutorial on agent-based modelling and simulation," Journal of Simulation, vol. 4, no. 3, pp. 151-162, 2010, http://dx.doi.org/10.1057/jos.2010.3.

[29] J. M. Epstein and R. L. Axtell, Growing artificial societies: Social science from the bottom up, Massachusetts Institute of Technology, Cambridge, USA, 1996.

[30] J. H. Holland and J. H. Miller, "Artificial adaptive agents in economic theory," The American Economic Review, vol. 81, pp. 365-370, 1991.

[31] V. Rai and S. A. Robinson, "Agent-based modeling of energy technology adoption: Empirical integration of social, behavioral, economic, and environmental factors," Environmental Modelling and Software, vol. 70, pp. 163177, 2015, http://www.sciencedirect.com/science/article/pii/ S1364815215001231?via\%3Dihub.
[32] J. Palmer, G. Sorda, and R. Madlener, "Modeling the diffusion of residential photovoltaic systems in Italy: An agent-based simulation," Technological Forecasting \& Social Change, vol. 99, pp. 106-131, 2015.

[33] G. Sorda, Y. Sunak, and R. Madlener, "An agent-based spatial simulation to evaluate the promotion of electricity from agricultural biogas plants in Germany," Ecological Economics, vol. 89, pp. 43-60, 2013.

[34] F. Genoese and M. Genoese, "Assessing the value of storage in a future energy system with a high share of renewable electricity generation," Energy Systems, vol. 5, no. 1, pp. 19-44, 2014.

[35] S. Yousefi, M. P. Moghaddam, and V. J. Majd, "Optimal real time pricing in an agent-based retail market using a comprehensive demand response model," Energy, vol. 36, no. 9, pp. 5716-5727, 2011.

[36] M. Zheng, C. J. Meinrenken, and K. S. Lackner, "Agent-based model for electricity consumption and storage to evaluate economic viability of tariff arbitrage for residential sector demand response," Applied Energy, vol. 126, pp. 297-306, 2014.

[37] Z. Zhou, F. Zhao, and J. Wang, "Agent-based electricity market simulation with demand response from commercial buildings," IEEE Transactions on Smart Grid, vol. 2, no. 4, pp. 580-588, 2011.

[38] A. Kowalska-Pyzalska, K. Maciejowska, K. Suszczyński, K. Sznajd-Weron, and R. Weron, "Turning green: Agent-based modeling of the adoption of dynamic electricity tariffs," Energy Policy, vol. 72, pp. 164-174, 2014.

[39] P. R. Thimmapuram and J. Kim, "Consumers' price elasticity of demand modeling with economic effects on electricity markets using an agent-based model," IEEE Transactions on Smart Grid, vol. 4, no. 1, pp. 390-397, 2013.

[40] T. Zhang and W. J. Nuttall, "Evaluating Government's Policies on Promoting Smart Metering Diffusion in Retail Electricity Markets via Agent-Based Simulation*," Journal of Product Innovation Management, vol. 28, no. 2, pp. 169-186, 2011.

[41] R. A. C. van der Veen, A. Abbasy, and R. A. Hakvoort, "Agentbased analysis of the impact of the imbalance pricing mechanism on market behavior in electricity balancing markets," Energy Economics, vol. 34, no. 4, pp. 874-881, 2012.

[42] F. Sensfuß, M. Ragwitz, and M. Genoese, "The merit-order effect: A detailed analysis of the price effect of renewable electricity generation on spot market prices in Germany," Energy Policy, vol. 36, no. 8, pp. 3076-3084, 2008.

[43] J. C. Richstein, E. J. L. Chappin, and L. J. de Vries, "Crossborder electricity market effects due to price caps in an emission trading system: An agent-based approach," Energy Policy, vol. 71, pp. 139-158, 2014.

[44] G. Li and J. Shi, "Agent-based modeling for trading wind power with uncertainty in the day-ahead wholesale electricity markets of single-sided auctions," Applied Energy, vol. 99, pp. 13-22, 2012.

[45] L. A. Wehinger, G. Hug-Glanzmann, M. D. Galus, and G. Andersson, "Modeling electricity wholesale markets with model predictive and profit maximizing agents," IEEE Transactions on Power Systems, vol. 28, no. 2, pp. 868-876, 2013.

[46] F. Sensuß, M. Genoese, M. Ragwitz, and D. Möst, "Agent-based Simulation of Electricity Markets -A Literature Review," Energy Studies Review, vol. 15, no. 2, 2007.

[47] P. Ringler, D. Keles, and W. Fichtner, "Agent-based modelling and simulation of smart electricity grids and markets - A literature review," Renewable \& Sustainable Energy Reviews, vol. 57, pp. 205-215, 2016. 
[48] S. Wassermann, M. Reeg, and K. Nienhaus, "Current challenges of Germany's energy transition project and competing strategies of challengers and incumbents: The case of direct marketing of electricity from renewable energy sources," Energy Policy, vol. 76, pp. 66-75, 2015.

[49] ENWG, "Gesetz über die Elektrizitäts- und Gasversorgung," Bundesanzeiger des Bundesministerium fr Justiz, 2005, https:// www.gesetze-im-internet.de/enwg_2005/.

[50] M. J. North, N. T. Collier, J. Ozik et al., "Complex adaptive systems modeling with Repast Simphony," Complex Adaptive Systems Modeling, vol. 1, no. 1, p. 3, 2013.

[51] N. Joachim, T. Pregger, T. Naegler et al., "Long-term scenarios and strategies for the deployment of renewable energies in Germany in view of European and global developments," DLR Portal, 2012, http://elib.dlr.de/76044/.

[52] Y. Scholz, Renewable energy based electricity supply at low costs: development of the REMix model and application for Europe [Ph.D. thesis], Universität Stuttgart, Germany, 2012.

[53] D. Stetter, Enhancement of the REMix energy system model: Global renewable energy potentials, optimized power plant siting and scenario validation [Ph.D. thesis], Universität Stuttgart, Germany, 2014.

[54] MaPrV, Verordnung über die Höhe der Managementprämie für Strom aus Windenergie und solarer Strahlungsenergie, 2012, https://www.clearingstelle-eeg.de/maprv.

[55] Übertragungsnetzbetreiber, https://www.netztransparenz.de/ EEG/Verguetungs-und-Umlagekategorien.

[56] AusglMechV., "Verordnung zur Weiterentwcklung des bundesweiten Ausgleichmechanismus," Bundesanzeiger des Bundesministerium für Justiz, 2010.

[57] V. Grimm, U. Berger, D. L. DeAngelis, J. G. Polhill, J. Giske, and S. F. Railsback, "The ODD protocol: A review and first update," Ecological Modelling, vol. 221, no. 23, pp. 2760-2768, 2010.

[58] P. Windrum, G. Fagiolo, and A. Moneta, "Empirical Validation of Agent-Based Models: Alternatives and Prospects," Journal of Artificial Societies and Social Simulation, vol. 10, no. 2, 2007, http://jasss.soc.surrey.ac.uk/10/2/8.html.

[59] I. Lorscheid, B.-O. Heine, and M. Meyer, "Opening the "black box" of simulations: increased transparency and effective communication through the systematic design of experiments," Computational and Mathematical Organization Theory, vol. 18, no. 1, pp. 22-62, 2012, https://doi.org/10.1007/s10588-011-9097-3.

[60] O. Weiss, D. Bogdanov, K. Salovaara, and S. Honkapuro, "Market designs for a $100 \%$ renewable energy system: Case isolated power system of Israel," Energy, vol. 119, pp. 266-277, 2017.

[61] C. M. Macal, "Everything you need to know about agent-based modelling and simulation," Journal of Simulation, vol. 10, no. 2, pp. 144-156, 2016.

[62] E. J. L. Chappin, Simulating Energy Transitions [Ph.D. thesis], TU Delft, 2011, http://resolver.tudelft.nl/uuid.

[63] F. W. Geels, “Technological transitions as evolutionary reconfiguration processes: A multi-level perspective and a case-study," Research Policy, vol. 31, no. 8-9, pp. 1257-1274, 2002. 


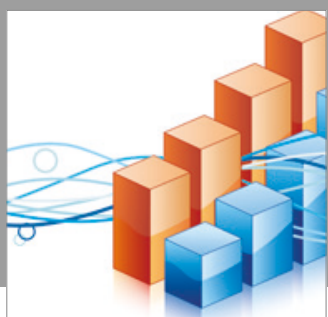

Advances in

Operations Research

vatersals

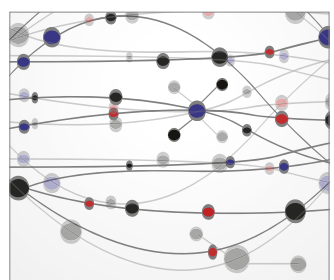

\section{The Scientific} World Journal
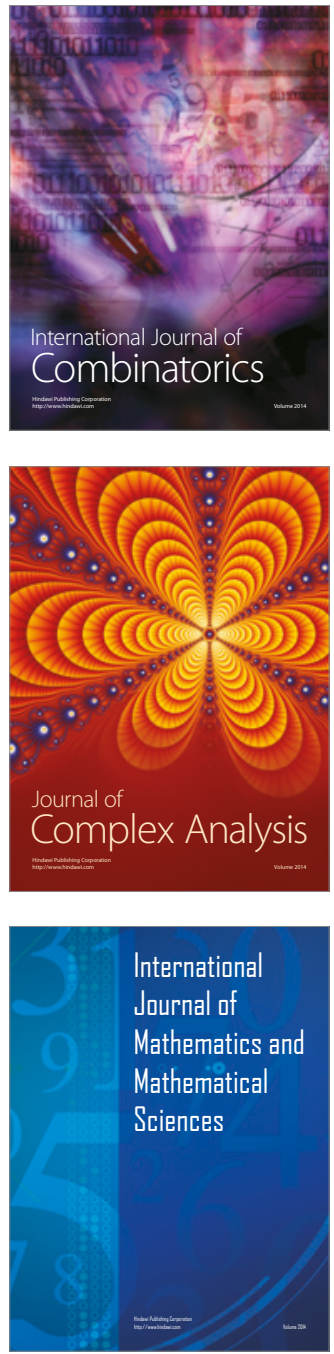
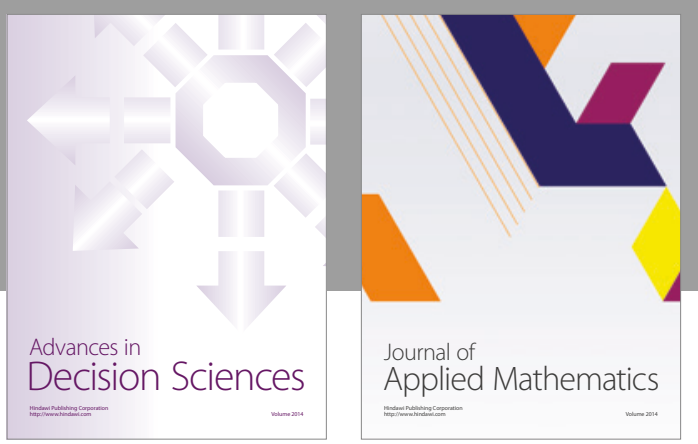

Algebra

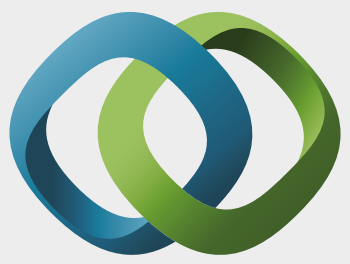

\section{Hindawi}

Submit your manuscripts at

https://www.hindawi.com
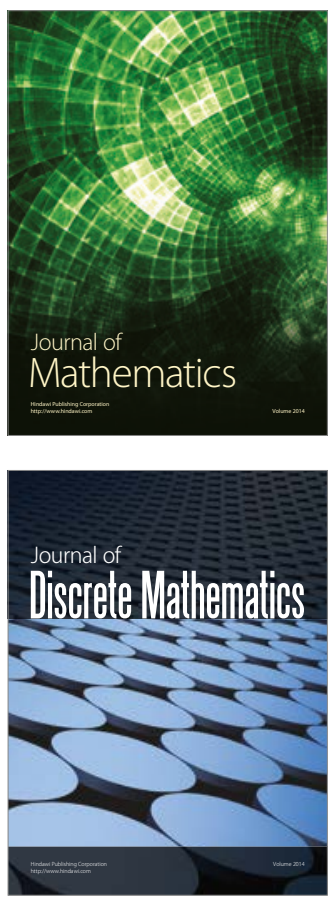

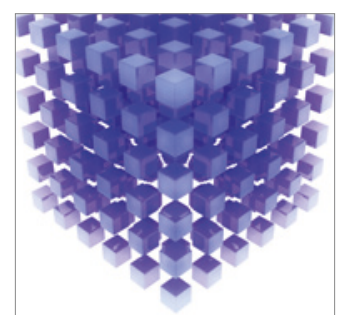

Mathematical Problems in Engineering
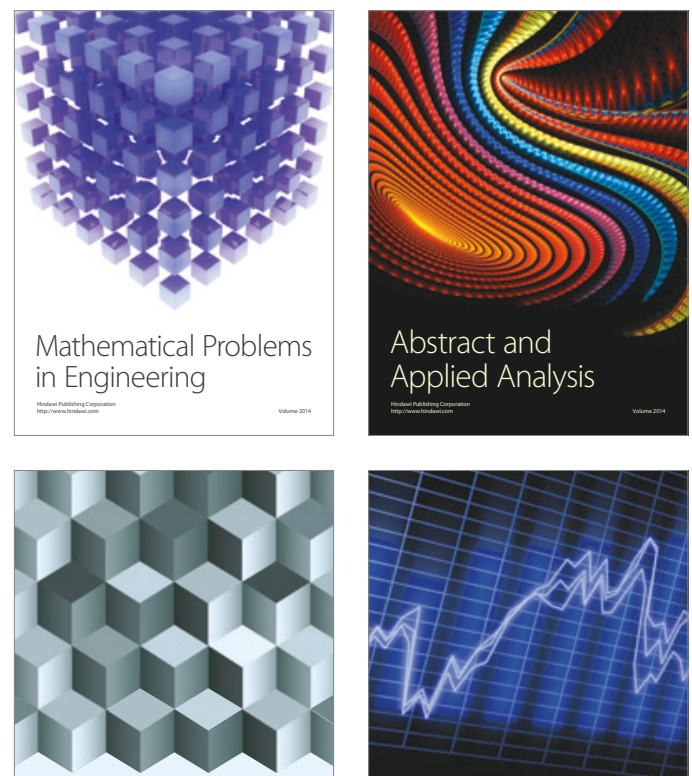

Journal of

Function Spaces

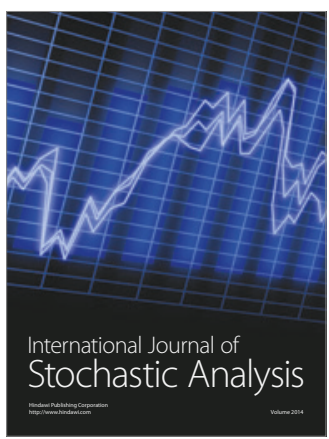

Probability and Statistics
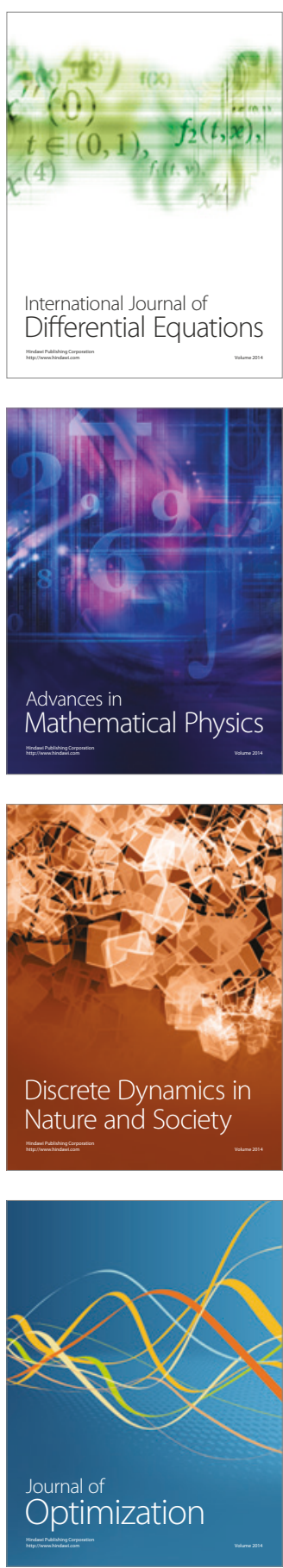